\title{
A novel model of acquired hydrocephalus for evaluation of neurosurgical treatments
}

\author{
James P. McAllister II ${ }^{1,9^{*}}$, Michael R. Talcott ${ }^{1,2}$, Albert M. Isaacs ${ }^{3}$, Sarah H. Zwick', Maria Garcia-Bonilla', \\ Leandro Castaneyra-Ruiz' ${ }^{1}$, Alexis L. Hartman' ${ }^{1}$, Ryan N. Dilger ${ }^{4,5}$, Stephen A. Fleming ${ }^{4,5}$, Rebecca K. Golden ${ }^{4}$, \\ Diego M. Morales ${ }^{1}$, Carolyn A. Harris ${ }^{6,7}$ and David D. Limbrick Jr ${ }^{1,8}$
}

\begin{abstract}
Background: Many animal models have been used to study the pathophysiology of hydrocephalus; most of these have been rodent models whose lissencephalic cerebral cortex may not respond to ventriculomegaly in the same way as gyrencephalic species and whose size is not amenable to evaluation of clinically relevant neurosurgical treatments. Fewer models of hydrocephalus in gyrencephalic species have been used; thus, we have expanded upon a porcine model of hydrocephalus in juvenile pigs and used it to explore surgical treatment methods.
\end{abstract}

Methods: Acquired hydrocephalus was induced in 33-41-day old pigs by percutaneous intracisternal injections of kaolin $(n=17)$. Controls consisted of sham saline-injected $(n=6)$ and intact $(n=4)$ animals. Magnetic resonance imaging (MRI) was employed to evaluate ventriculomegaly at 11-42 days post-kaolin and to plan the surgical implantation of ventriculoperitoneal shunts at 14-38-days post-kaolin. Behavioral and neurological status were assessed.

Results: Bilateral ventriculomegaly occurred post-induction in all regions of the cerebral ventricles, with prominent CSF flow voids in the third ventricle, foramina of Monro, and cerebral aqueduct. Kaolin deposits formed a solid cast in the basal cisterns but the cisterna magna was patent. In 17 untreated hydrocephalic animals. Mean total ventricular volume was $8898 \pm 5917$ SD mm m $^{3}$ at 11-43 days of age, which was significantly larger than the baseline values of $2251 \pm 194$ SD mm for $^{3}$ sham controls aged $45-55$ days, $(p<0.001)$. Past the post-induction recovery period, untreated pigs were asymptomatic despite exhibiting mild-moderate ventriculomegaly. Three out of 4 shunted animals showed a reduction in ventricular volume after 20-30 days of treatment, however some developed ataxia and lethargy, from putative shunt malfunction.

Conclusions: Kaolin induction of acquired hydrocephalus in juvenile pigs produced an in vivo model that is highly translational, allowing systematic studies of the pathophysiology and clinical treatment of hydrocephalus.

Keywords: Hydrocephalus, Animal models, Kaolin, Acquired hydrocephalus, Shunt, Ventriculomegaly, Cognition

\section{Introduction}

Hydrocephalus is a common neurological disorder in all ages [1-7] that is characterized by enlargement of the cerebral ventricles and often increased intracranial pressure. At present, treatment is limited to surgical diversion

\footnotetext{
*Correspondence: pat.mcallister@wustl.edu

${ }^{9}$ Department of Neurosurgery, BJC Institute of Health, 425 S. Euclid, Campus, Box 8057, St. Louis, MO 63143, USA

Full list of author information is available at the end of the article
}

(shunt treatment) of cerebrospinal fluid (CSF) from the cerebral ventricles to alternative absorption sites or to endoscopic third ventriculostomy (ETV) with or without choroid plexus cauterization (CPC). Functional outcomes are problematic, with residual neurological and cognitive deficits prevalent in $25-80 \%$ of patients [1, 8-13].

A primary barrier to progress in improving treatments for hydrocephalus is a lack of large animal models of this disorder to elucidate the multifactorial pathophysiology 
of hydrocephalus and evaluate the effects of suboptimal surgical treatments [13, 14]. A major distinction involves the structural complexities of the brain, especially the differential responses to ventriculomegaly between lissencephalic and gyrencephalic species. Vink [15] has admirably reviewed this comparison in models of traumatic brain injury, noting the key biomechanical differences in gyrencephalic brains (porcine, canine, ovine, lagomorph, and non-human primate) that diffuse the pattern of pathology throughout the cerebral cortex and periventricular white matter as compared to lissencephalic species (mouse, rat). Most basic studies on the pathophysiology of hydrocephalus have used mouse and rat models, not large animals; the species differences have been implicated in the failure of many therapeutic studies in subsequent clinical trials, especially for traumatic brain injury $[16,17]$. The lack of large animal models also impedes the development of improved shunting systems and novel surgical procedures, as well as pharmacological approaches designed to protect and/or repair the hydrocephalic brain. The need for large animal models of hydrocephalus has been recognized by the United States National Institutes of Health, who have sought to address this issue with PA-18-623, "Tools to Enhance the Study of Prenatal and Pediatric Hydrocephalus".

Several gyrencephalic animal models of hydrocephalus have been utilized for experimental studies, including dogs [18-39], cats [40-59], ferrets [60-62], sheep [63-69], pigs [70, 71], and non-human primates [72-74]. Dogs and cats have been widely employed, especially in studies of CSF physiology and intracranial pressure; however, ethical concerns largely prevent their use today. Ferrets represent an excellent model of pre-term hydrocephalus due to the relative immaturity of their brains at birth [75], but they are too small to accommodate clinically-relevant shunt hardware or to perform novel techniques such as ETV $\pm \mathrm{CPC}$. Non-human primates have the advantage of being bipedal, but their use is cost prohibitive. Following a widely-used procedure in which the inert mineral kaolin is injected into the cisterna magna, fetal lambs develop hydrocephalus [65, 68, 76]. Johnston and colleagues expanded this model in adult sheep and provided preliminary observations on cytopathology and catheter obstruction following ventriculoperitoneal shunting. Unfortunately, sheep present several postoperative veterinary challenges, not the least of which is managing the potential exposure to biohazards, including Coxiella burnetti (Q-fever) [77]. Neonatal and adult pigs have also been used to model hydrocephalus following aqueductal stenosis [78] and intraventricular hemorrhage [70, 79-81]. The latter have provided valuable information on the pathogenesis and pathophysiology of post-hemorrhagic hydrocephalus. Except for preliminary attempts to reduce blood clot formation with recombinant tissue plasminogen activator delivered through an external ventricular drain [70,81], these porcine studies did not include surgical shunting.

The domestic pig (Sus scrofa) is a preferred pre-clinical model because of its anatomic and physiologic similarities to humans, i.e. gyral patterns, 60:40 white:gray matter ratios [82-84], as well as similar brain growth and development timelines (maximum brain growth is late prenatal to early postnatal in both domestic pigs and humans) [83-87]. Advanced neuroimaging is often conducted on pigs [87-91], and the size of a pig brain [87] permits CSF shunting with clinical hardware. Juvenile pigs are amenable to the induction of hydrocephalus via intracisternal injections of kaolin or intraventricular injections of blood [70, 79-81, 92, 93]. Furthermore, stereotactic coordinates of the pig brain are well known [89, 94, 95]. Finally, cognitive testing is now available through the development of novel object recognition techniques in maturing pigs $[96,97]$.

To advance clinically relevant studies on the pathophysiology and treatment of hydrocephalus, we have developed a large animal model of juvenile hydrocephalus, induced with intracisternal kaolin injections, that can be used to test surgical treatments with clinical instrumentation. This report describes the methodology of this model and the initial observations on neuroimaging, ventriculomegaly, surgical treatment with ventriculoperitoneal shunting, and cognitive testing.

\section{Materials and methods}

Experimental design

Four experimental groups were studied in juvenile pigs (Table 1): (1) Untreated Hydrocephalus-animals that developed ventriculomegaly following intracisternal kaolin injections $(\mathrm{n}=9)$; (2) Shunt-treated Hydrocephalus-animals with ventriculomegaly that received ventriculoperitoneal (VP) shunts for diversion of CSF $(\mathrm{n}=8)$; (3) Sham Controls-animals that received intracisternal saline injections $(n=6)$; and (4) Intact Controls-normal naïve animals, only used for pre-induction MRI $(n=4)$. All groups were age-matched. Outcomes included pre- and post-induction behavior, neurological status, cognitive testing, neuroimaging with T1- and T2-weighted MRI, ventricular volume quantification from T2-weighted MRI scans, and gross brain morphology including subjective assessments of ventricular catheter patency; e.g., inspection of the catheter lumen for tissue or debris. In addition to the Untreated Hydrocephalus cases described above, 31 kaolin-injected untreated pigs were evaluated with MRI to subjectively assess the success rate of kaolin induction. 
Table 1 Summary of cases

\begin{tabular}{|c|c|c|c|c|c|c|c|c|}
\hline $\begin{array}{l}\text { Case } \\
\#\end{array}$ & Condition & $\begin{array}{l}\text { Age at } \\
\text { induction } \\
\text { (days) }\end{array}$ & $\begin{array}{l}\text { Age at post- } \\
\text { induction MRI } \\
\text { (days) }\end{array}$ & $\begin{array}{l}\text { Age at } \\
\text { shunt } \\
\text { treatment } \\
\text { (days) }\end{array}$ & $\begin{array}{l}\text { Age at Post- } \\
\text { shunt MRI (days) }\end{array}$ & $\begin{array}{l}\text { Survival } \\
\text { age (days) }\end{array}$ & $\begin{array}{l}\text { Duration } \\
\text { Post-kaolin or } \\
\text { post-shunt } \\
\text { (days) }\end{array}$ & $\begin{array}{l}\text { Total } \\
\text { ventricular } \\
\text { volume }\left(\mathrm{mm}^{3}\right)^{*}\end{array}$ \\
\hline 1 & UH & 35 & 78 & & & 85 & 43 & 3310 \\
\hline 2 & UH & 35 & 76 & & & 85 & 41 & 3350 \\
\hline 3 & UH & 35 & 64 & & & 70 & 29 & 3027 \\
\hline 4 & UH & 35 & 58 & & & 70 & 23 & 3592 \\
\hline 5 & UH & 33 & 69 & & & 69 & 36 & 16,145 \\
\hline 6 & UH & 33 & 69 & & & 69 & 36 & 12,802 \\
\hline 7 & UH & 35 & 77 & & & 77 & 42 & 4391 \\
\hline 8 & UH & 36 & 56 & & & 55 & 20 & 4601 \\
\hline 9 & UH & 33 & 47 & & & 81 & 14 & 20,824 \\
\hline 10 & $\mathrm{SH}$ & 37 & 48 & 53 & 81 & 81 & 28 & $3805 / 34127$ \\
\hline 11 & $\mathrm{SH}$ & 35 & 52 & 70 & NA & 80 & 10 & $3899 / \mathrm{NA}$ \\
\hline 12 & $\mathrm{SH}$ & 33 & 45 & 49 & 79 & 79 & 20 & $10,496 / 30533$ \\
\hline 13 & $\mathrm{SH}$ & 39 & 57 & 62 & 92 & 78 & 16 & $11,051 / 9035$ \\
\hline 14 & $\mathrm{SH}$ & 34 & 72 & 79 & NA & 84 & 5 & 9194/NA \\
\hline 15 & $\mathrm{SH}$ & 36 & 58 & 64 & NA & 94 & 30 & $12,710 / \mathrm{NA}$ \\
\hline 16 & $\mathrm{SH}$ & 36 & 58 & 63 & NA & 94 & 31 & $21,778 / \mathrm{NA}$ \\
\hline 17 & $\mathrm{SH}$ & 41 & 52 & 55 & 86 & 110 & 55 & $9554 / 6503$ \\
\hline 18 & SC & 44 & 53 & & & 83 & & 2248 \\
\hline 19 & SC & 44 & 45 & & & 83 & & 2226 \\
\hline 20 & SC & 46 & 54 & & & 93 & & 2314 \\
\hline 21 & SC & 46 & 55 & & & 93 & & 2241 \\
\hline 22 & SC & 45 & 51 & & & 82 & & 2571 \\
\hline 23 & SC & 42 & 51 & & & 82 & & 1906 \\
\hline 24 & IC & & 34 & & & 21 & & 2015 \\
\hline 25 & IC & & 41 & & & 89 & & 2230 \\
\hline 26 & IC & & 37 & & & 54 & & 2493 \\
\hline 27 & IC & & 37 & & & 72 & & 1793 \\
\hline Misc & UH & $28-35$ & $38-82$ & & & $38-82$ & $10-51$ & Not used \\
\hline
\end{tabular}

*In cases with 2 ventricular volumes, the first number is the pre-shunt (untreated) condition and the second is the post-shunt condition

All procedures were approved by the Washington University Institutional Animal Care and Use Committee and done in an American Association for Accreditation of Laboratory Animal Care (AAALAC)-accredited facility in compliance with the Guide for the Care and Use of Laboratory Animals and the Animal Welfare Act. Juvenile ( $\sim 30$-day old) domestic pigs (Sus scrofa domesticus) were obtained from a university approved vendor (Oak Hill Genetics LLC, Ewing, IL) and maintained in standard pens with raised flooring, fed a standard pig chow (Purina Porcine Grower Diet 5084) with ad lib access to water. Pigs were allowed to acclimate to the facility and physical exams were performed by institutional veterinary staff to assure normal health and behavior. Our study corresponds to the USDA Class D category of animal use. All animals undergoing surgery received surgical pre-anesthetics and analgesics, intra-operative anesthetics, and post-operative medications as needed (Additional file 5: Table 1).

\section{Induction of hydrocephalus}

Pigs were sedated with a cocktail of telazol, ketamine, and xylazine (1.0 ml/50 lb intramuscular), intubated, and maintained under general anesthesia using 1-4\% Isoflurane. The dorsal neck and head were shaved free of hair and the area was surgically prepped using povidone iodine and alcohol after the pig was positioned in a lateral decubitus position. Importantly, the head was temporarily flexed to about 90-degrees to open the atlanto-occipital interval as much as possible, with care taken to maintain a patent airway. Using sterile technique, a wellaccepted method was employed to induce hydrocephalus 
[45, 51-53]: the cisterna magna was tapped percutaneously with an 18-gauge spinal needle (Becton-Dickenson 405184, McKesson Medical-Surgical. Richmond, VA) inserted in the midline at a $45^{\circ}$ angle to the skin of the dorsal neck. The cisterna magna was located by manually sensing the needle tip as it contacted the flexible atlantooccipital membrane and dura; if the occipital bone was encountered during penetration, the needle was "walked" inferiorly without withdrawing until the atlanto-occipital membrane was encountered. Accurate placement was confirmed when CSF was seen in the hub of the needle when the needle stylet was withdrawn. CSF was allowed to drip from the needle hub to confirm placement within the cisterna magna and checked for blood contamination. An IV extension tubing (B. Braun, ET12SB) was connected to the spinal needle and $1.25 \mathrm{ml}$ of sterile $25 \%$ kaolin was injected slowly (about $0.25 \mathrm{ml} / \mathrm{min}$ ) into the cisterna magna. After a 1-2-min equilibration period to allow dispersion of the kaolin, the IV extension tubing was disconnected from the spinal needle, and continued accurate placement was confirmed by observing a small amount of CSF mixed with kaolin emerging from the needle hub. The needle was withdrawn and the animal allowed to recover from anesthesia using standard veterinary procedures. When the animal could stand, it was placed in a recovery pen for $24-48 \mathrm{~h}$ and subsequently returned to its home cage.

\section{Surgical treatment with ventriculoperitoneal shunts}

Following induction of hydrocephalus, standard VP shunts were placed because they are used almost exclusively to treat pediatric patients with hydrocephalus. We used CSF-Flow Control Shunt Kits (low-pressure valve/reservoir, model 9003D, Medtronic Neurosurgery, Goleta, CA, USA). Shunts were placed at 53-79 days of age, depending on the progression of hydrocephalus (primarily ventriculomegaly severity and neurological status) using similar neurosurgical procedures performed on human patients and feline models [50, 52]. Animals were anesthetized as described previously for the kaolin inductions. A 3-5 cm skin incision was made in the midline dorsal neck over the nuchal crest. The attaching occipital tissue was blunt-dissected off the occipital bone, with minimal use of bipolar cautery to release the muscle attachments. The muscle and skin were retracted to expose the occipital bone $\sim 1 \mathrm{~cm}$ lateral to the midline on either side. A unilateral burr hole $(\sim 2.5 \mathrm{~cm}$ diameter) was made with a drill, the underlying dura mater was preserved, and any bone bleeding was stopped with bone wax. The location of this burr hole was determined from a pre-shunt MRI; this was usually centered $8.0-10.0 \mathrm{~mm}$ lateral to the midline and $10.0-12.0 \mathrm{~mm}$ inferior to the nuchal crest. Once the dura was exposed, attention was turned to the lateral thorax and abdomen for placement of the distal catheter. Two small $(\sim 1 \mathrm{~cm})$ skin incisions were made; one over the left lateral rib cage for passing the distal catheter and inserting the valve with its reservoir and the other over the left abdomen $\sim 1 \mathrm{~cm}$ caudal to the lowest rib for insertion of the peritoneal end of the distal catheter. The abdominal incision was dissected bluntly until the peritoneal layer was encountered. Two Crile hemostats were used to grasp the peritoneal layer and a small incision $\sim 0.25 \mathrm{~cm}$ was made to expose the peritoneal cavity. A \#1 Penfield instrument was inserted to confirm the peritoneal cavity had been accessed. A tunneler (Medtronic Neurosurgery, Goleta, CA, USA) was passed subcutaneously from the incision over the rib cage to the abdominal wound. A standard shunt catheter, distal slit valves removed, was then passed through the tunneler and inserted into the peritoneal cavity to a depth of about $20 \mathrm{~cm}$. The proximal end of the subcutaneous catheter was attached to the distal port of a shunt valve and secured with 3-0 silk ties. A second portion of shunt tubing was passed subcutaneously from the occipital region to the rib cage incision using the same tunneling technique. The distal end of this catheter was attached to the proximal end of a reservoir with a lowpressure valve and secured with 3-0 silk ties. The valve was then positioned within a subcutaneous pocket over the rib cage and secured to underlying muscle and fascia with absorbable sutures. Once the subcutaneous portion of the shunt system had been completed, attention returned to the occipital area. Within the occipital craniotomy, bipolar cautery was used to coagulate the dura mater, which was then incised in a cruciate fashion with a \#11 scalpel blade. The ventricular catheter was inserted through the opening in the dura mater and advanced through the occipital cortex into the lateral ventricle to a depth of about $2.5-3.5 \mathrm{~cm}$ from the occipital skull surface, based on pre-shunt measurements calculated from the MR images. Placement of the ventricular catheter in the lateral ventricle was confirmed by the appearance of CSF in the extracranial portions of the catheter. The ventricular catheter was anchored to the skull with Nylon sutures into the pericranium with or without a plastic anchor secured to the skull with self-tapping screws (Titanium cranial fixation system, Medtronic Brain Therapies, Irvine, CA, USA). The abdominal wall and chest incisions were closed in layers in a standard fashion with absorbable sutures. The cranial incision was closed in a layered fashion with absorbable sutures used to approximate the dorsal cervical muscles and overlying fascia in continuity with the galea aponeurotica. The skin was closed with subcuticular absorbable sutures and external interrupted 
3-0 ETHILON ${ }^{\circledR}$ nylon non-absorbable sutures. External sutures were removed when the skin had healed, approximately 10 -days post-surgery.

\section{Post-operative and post-MRI monitoring}

During the recovery period (i.e., until a sternal position and/or standing could be achieved), animals were monitored every $15 \mathrm{~min}$ and vital signs recorded. Subsequently, monitoring was conducted about every $4-8 \mathrm{~h}$ until the animals could nourish themselves and displayed no neurological symptoms or signs of pain and discomfort (i.e., about 1-2 days),. After this period of recovery, daily monitoring was conducted to assure normal recovery from anesthesia following the MRI scans and the surgical procedures (i.e., healing of incisions, tissue swelling, integrity of the distal catheter track). The animal's neurological status (i.e., general locomotor and sensorimotor behavior, ataxia, balance, alertness, reflexes, and ability to eat and drink) was also monitored. Body temperature and clinical activity during recovery were monitored closely as lethargy and hyperthermia/fever were often observed after kaolin injections. Acute neurological and behavioral signs and symptoms were managed medically with Buprenorphine/Buprenex, Tylenol/acetaminophen suppository, Carprofen/Rimadyl, Dexamethasone, Keppra, and occasional alcohol baths for hyperthermia (Additional file 5: Table 1).

\section{Neuroimaging and ventricular volume analyses}

Anatomic MRI imaging was used to guide surgical implantation of ventricular catheters and determine gross morphological changes in the brain, especially volumetric increases in the cerebral ventricles, the location of the kaolin deposits, and the position of ventricular catheters. When possible, neuroimaging was performed pre-induction, post-induction/pre-shunting, and postshunt on a Siemens Prisma 3.0-Tesla MR scanner with a $60-\mathrm{cm}$ clear bore diameter, a 20-channel head coil, an $80 \mathrm{mT} / \mathrm{m}$ gradient field, and a slew rate of $200 \mathrm{mT} / \mathrm{ms}$. The pig was anesthetized as described for hydrocephalus induction and positioned supine in the magnet. Breathing was controlled with a ventilator, respiratory and heart rates were monitored every $15 \mathrm{~min}$, and oxygen saturation was monitored continuously with a pulse oximeter (Nonin ${ }^{\circledR} 7500$, Nonin Medical, Plymouth, MN) secured to the tail. Depending on brain size, 54-192 slices of T1- and T2-weighted images were collected with a 3D fast spin-echo sequence with an echo train length of 8 , FOV $205 \times 205 \mathrm{~mm}(256 \times 256$ voxels $)$, and a voxel size of $0.8 \mathrm{~mm}$. T1 and T2 MPRAGE scan time varied from 4-11 min (T1:TR $2300 \mathrm{~ms}$, TE $2.36 \mathrm{~ms}, 2$ averages; T2: TR 3200 ms, TE 409 ms, 2 averages). Slice thickness was
$900 \mu \mathrm{m}$. Data were provided in DICOM format (Digital Imaging and Communications in Medicine, standard for medical neuroimaging data).

Ventricular volume segmentation was performed using the free open-source software programs ITK-SNAP version 3.6.0 (http://www.itksnap.org/pmwiki/pmwiki.php). In ITK-SNAP, semi-autonomous methods were then used to separately label the lateral, third, fourth, and olfactory ventricles in each slice of the sagittal, axial (horizontal), and coronal view planes. Ventricular volume $\left(\mathrm{mm}^{3}\right)$ for each case was obtained using the Volumes and Statistics tool within the Segmentation menu.

\section{Behavioral and cognitive testing}

Well-established and validated tests developed by Dilger and Fleming [96-99] were used to quantify cognitive function prior to and following hydrocephalus induction using novel object recognition (NOR) tasks. NOR can reliably identify cognitive differences in infant pigs and is sensitive to small differences between treatment groups, as exemplified in a recent trial of dietary milk supplementation by Fleming et al. [98]. Using an arena designed from a standard housing pen with opaque walls and door and various objects secured to the floor, pigs were given two 10-min habituation periods over 2 days to explore the empty arena. The following day, they were then given $5 \mathrm{~min}$ to become familiar with 2 identical objects (sample trial). After a 24-h delay period, they were then given 5 min to explore 1 familiar object from the sample trial and 1 novel object (test trial). Each trial was recorded with a video camera suspended over the arena. A single, unbiased (i.e., blinded to treatment group), trained observer annotated and scored the continuous recordings to make the following measurements: (1) the number of visits to novel/sample objects, (2) time investigating novel/sample objects, (3) mean length of time per visit to an object, (4) latency to the first object visit, and (5) latency to the last object visit. The primary outcome for cognition was the Recognition Index (RI), which was calculated as the proportion of time each pig spent actively investigating the novel object as a proportion of the total active exploration time of both objects during the test trial. RI significantly $>0.50$ indicates novelty preference and thus recognition memory $[96,98]$.

\section{Euthanasia and brain fixation}

At designated time points, animals were sedated and anesthetized with Isoflurane and heparin was administered IV to facilitate cardiac perfusion. The anesthetized animals were euthanized using intravenous sodium pentobarbital $(120 \mathrm{mg} / \mathrm{kg}$ intraperitoneal) or isoflurane ( $5 \%$ inhalation) and following cardiac 
arrest the chest was opened. The descending thoracic aorta was clamped, the pericardium opened, the right atrium incised to allow intracardiac perfusion, first with Phosphate-Buffered Saline (PBS) or sterile saline delivered via a peristaltic pump (Cole Parmer Masterflex L/S Easy load II, Vernon Hills, IL, USA) through a blunt 13-gauge needle inserted into the left ventricle followed by $4 \%$ paraformaldehyde (Sigma-Aldrich, St. Louis, MO, USA) in PBS to complete fixation. Depending on the size of the pig, 5-7 l of each solution were needed for adequate brain fixation. The brain and shunt system were removed using gross dissection and stored in fixative for $48 \mathrm{~h}$ and subsequently in $70 \%$ ethyl alcohol.

\section{Data analysis}

For ventricular volume comparisons between sham controls and kaolin-injected animals, when a KruskalWallis test indicated non-normal distribution of data, an unpaired $t$-test with Welch's correction was used for non-parametric analyses. The primary outcome of cognitive function (i.e., learning and memory) was the Recognition Index (RI), which when altered significantly indicates novelty preference and thus Recognition Memory (RM) [96]. The linear mixed effects model was used to evaluate RM; this model is specified with RI as the outcome variable and a random intercept for animal. All data were reported as mean + standard deviation (SD) with statistical significance $<0.05$.

\section{Results}

Cases

Altogether, 27 cases (of the 58 total) contributed ventricular volume and survival data to this report (Table 1), as follows: (A) Untreated, kaolin-induced hydrocephalic pigs $(n=9)$ survived to euthanization at an age of 55-85 (median 70) days. (B) Shunt-treated hydrocephalic pigs $(\mathrm{n}=8)$ received VP shunts at 53-79 days of age and survived until euthanization at 78-110 days of age (median 81). Amongst the group of shunted pigs, 8 contributed to the untreated ventricular volume analysis (i.e., pre-shunt) whereas only 4 contributed to the post-shunt ventricular volume analysis. Controls included 6 sham/salineinjected pigs that survived 82-93 (median 83) days and 4 intact/non-injected animals that underwent neuroimaging at the approximate age at which experimental animals received kaolin, i.e., 34-41 (median 37) days of age.

\section{Post-induction results-kaolin obstruction and ventriculomegaly}

In addition to the 17 hydrocephalic cases used for the ventricular volume analysis, 31 kaolin-induced cases were also studied for other purposes $(n=48)$. Altogether, these results showed that $85.4 \%$ (41/48 cases) of kaolin injections produced ventriculomegaly.

In all kaolin-injected animals, at post-mortem examination, kaolin deposits consistently formed a solid cast within the basal cisterns (pontine, cerebellopontine angle, interpeduncular, and prepontine) and occasionally within the cistern of the lamina terminalis (Figures 1,
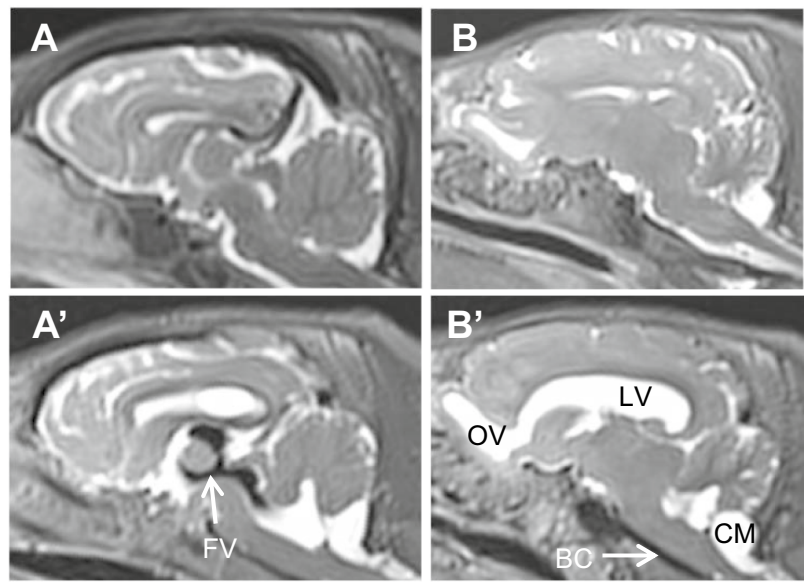
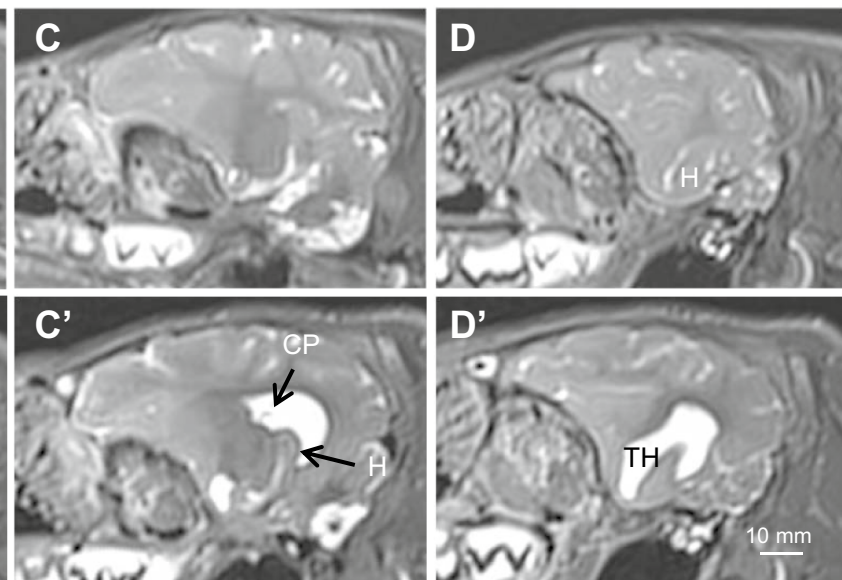

Fig. 1 Representative T2-weighted sagittal MRI images summarizing brain and ventricular morphology in non-hydrocephalic control (A-D) and hydrocephalic kaolin-injected pre-shunt conditions $\left(\mathbf{A}^{\prime}-\mathbf{D}^{\prime}\right)$; panels arranged left to right from midsagittal $\left(\mathbf{A}, \mathbf{A}^{\prime}\right)$ to lateral $\left(\mathbf{D}, \mathbf{D}^{\prime}\right)$. The intact control piglet (case 25) is 41-days old. Pre-shunt images are taken from case 13 at 18-days post-kaolin. In the pre-shunt condition, note the kaolin blockage of the basal cisterns (BC), prominent flow void (FV, black) within the third ventricle and cerebral aqueduct indicative of high CSF pulsatility, the patent channel connecting the olfactory ventricle (OV) to the lateral ventricle (LV), the choroid plexus (CP) floating in the LV, and the enlargement of all cerebral ventricles, especially the temporal horns $(\mathrm{TH})$ containing the hippocampus $(\mathrm{H})$, but no periventricular edema. The cisterna magna (CM) remains open. Scale bar $=10 \mathrm{~mm}$ for each all panels 
2, 3; Additional file 1: Figure S1, Additional file 2: Figure S2). Kaolin particles were rarely found within the cistern magna and never within the 4th- or 3rd-ventricles, the cerebral aqueduct, or the lateral ventricles. The basal cistern deposits could be identified on MRI throughout the post-induction and post-treatment survival periods on T2-weighted MRI scans (Figures $1 \mathrm{~B}^{\prime}$ and $3 \mathrm{~A}^{\prime \prime}$ ) and were accompanied by arachnoiditis and adherence to the dura mater or membrane of Liliquist. In about half of the cases, thin, patchy kaolin deposits were found in the subarachnoid space surrounding the base of the hypothalamus and the pituitary gland. No kaolin deposits entered the parenchyma or any of the cerebral ventricles. The basilar artery and its branches were completely embedded in the kaolin cast.

Bilateral, symmetrical ventriculomegaly occurred in most cases. In 2 cases $(<5)$, subsequent kaolin injections were needed to produce ventriculomegaly. All portions of the cerebral ventricles expanded, but no periventricular edema developed (Figures 1-3; Additional file 1: Figure S1, Additional file 2: Figure S2). It is noteworthy that olfactory ventricles were present normally in the domestic pig brain, each with a narrow channel connected to the frontal horn of each lateral ventricle; both the olfactory ventricle and the connecting channel expanded postkaolin. The cisterna magna remained open and enlarged, with a thin membranous anterior wall that appeared to separate it from the 4th ventricle. Prominent CSF flow voids, indicative of high pulsatility, were conspicuous in the foramina of Monro, 3rd ventricle, and anterior cerebral aqueduct. The cerebral hemispheres remained gyrencephalic with relatively little distortion of the sulci and gyri. In contrast, the inferior wall of the temporal lobe became extremely thin in response to the considerable expansion of the temporal horn of the lateral ventricle (Figures $1 \mathrm{D}^{\prime}$ and $3 \mathrm{D}^{\prime \prime}$, and Additional file 2: Figure S2E).

Volumetric assessments revealed that ventriculomegaly occurred post-induction in all cerebral ventricles
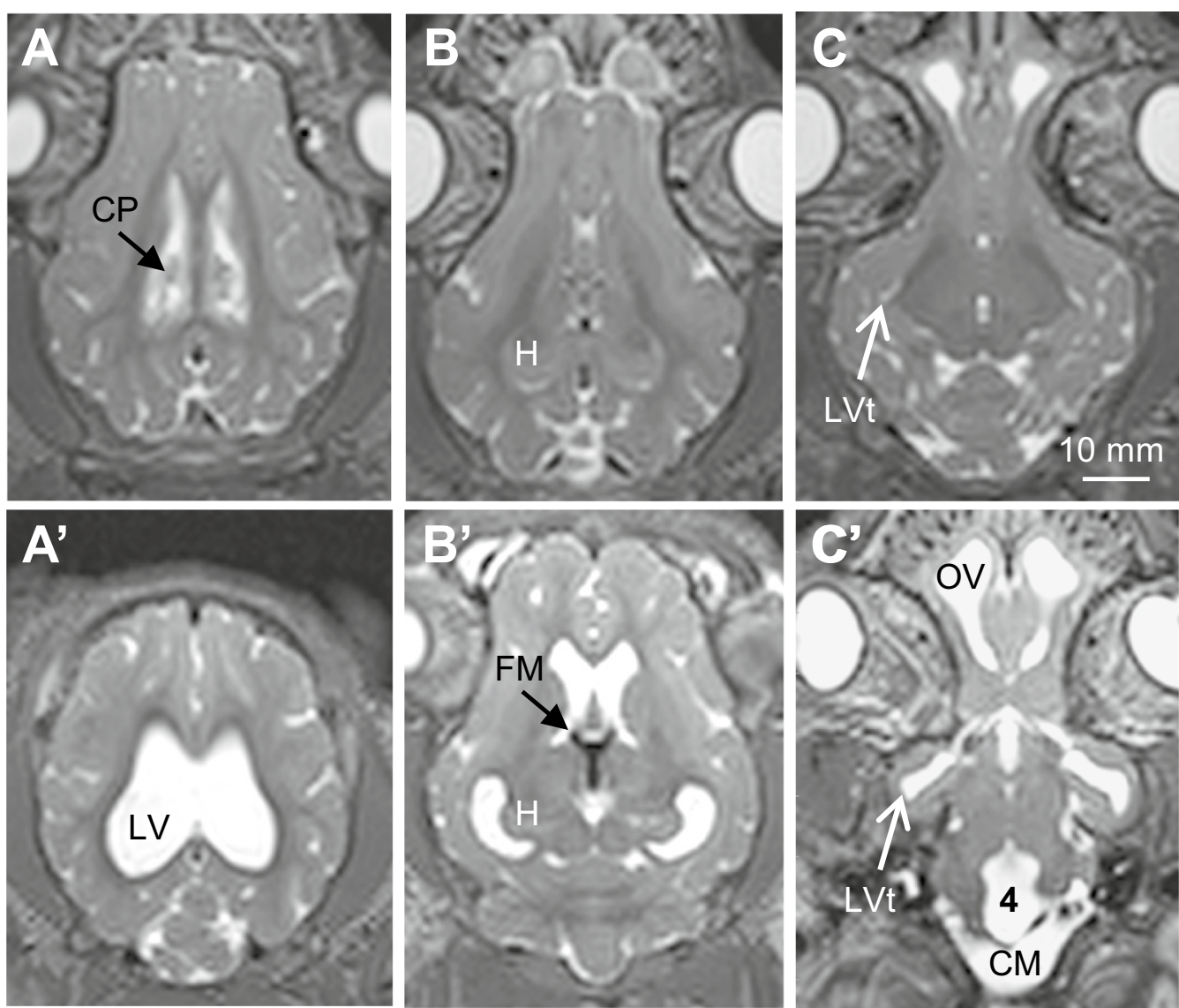

Fig. 2 Representative T2-weighted axial MRI images summarizing brain and ventricular morphology in non-hydrocephalic control (A-C) and hydrocephalic pre-shunt $\left(\mathbf{A}^{\prime}-\mathbf{C}^{\prime}\right)$ pigs. The intact control piglet (case 25) is 41-days old. Pre-shunt images are taken from case 13 at 18-days post-kaolin. In the pre-shunt condition, note the enlargement of all cerebral ventricles and the cisterna magna (CM), prominent flow voids (black) within the foramina of Monro (FM) and third ventricle indicative of high CSF pulsatility, the large olfactory ventricle (OV), and the choroid plexus (CP) in the lateral ventricle (LV). 4_fourth ventricle, $\mathrm{H}$-hippocampus, LVt—-temporal horn of the lateral ventricle. Scale bar $=10 \mathrm{~mm}$ for all panels 

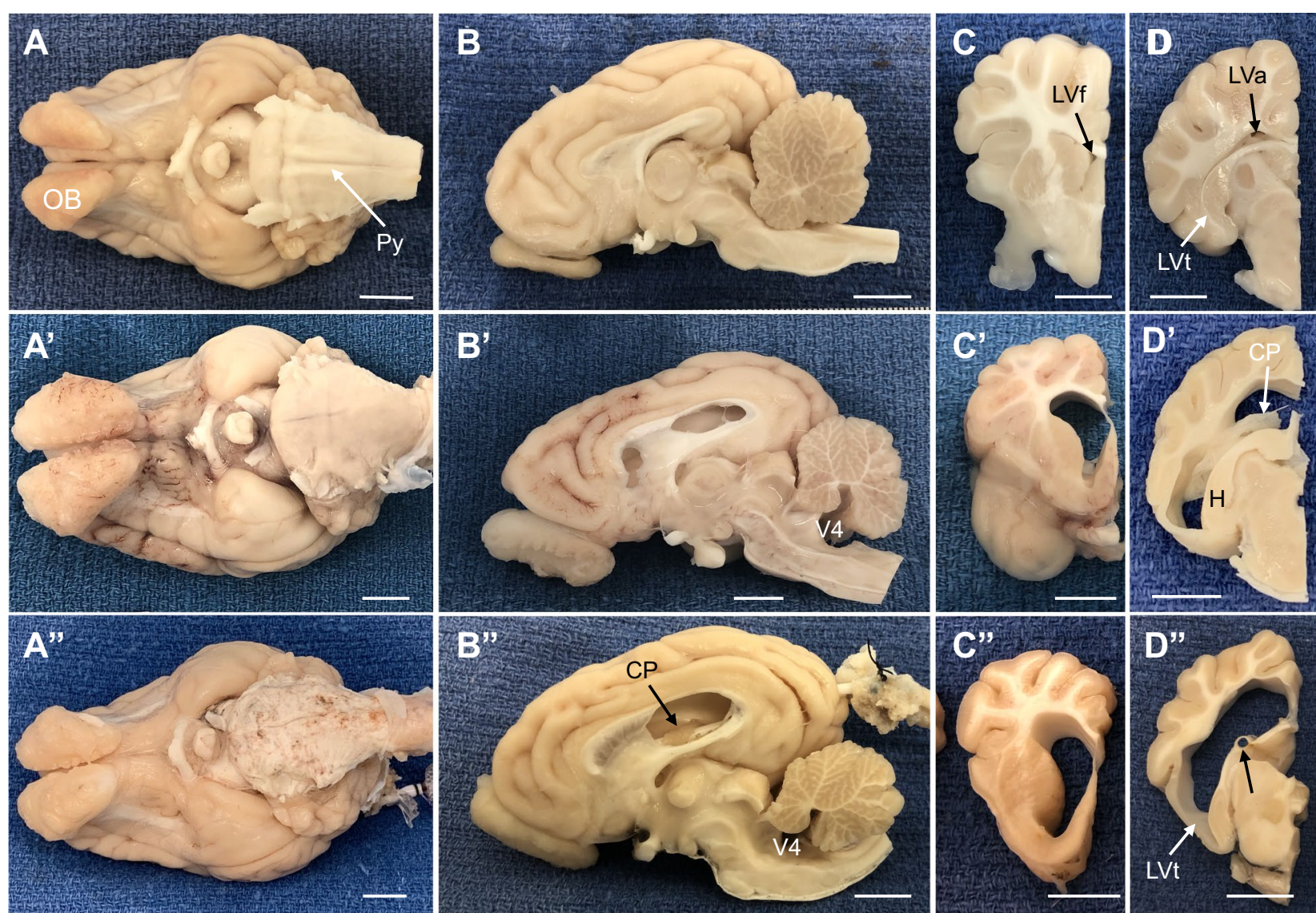

Fig. 3 Representative gross morphological features of post-mortem non-hydrocephalic and untreated hydrocephalic pig brains (cases 21 and 9 , respectively). In all cases, $C$ and D columns contain coronal views from the same case as the midsagittal section in B. A-D In a sham control 93-day old animal, the myelinated pyramids (Py) were prominent and the atria (LVa), frontal horns (LVf), and temporal horns (LVt) of the lateral ventricle were small or slit-like. $\mathbf{A}^{\prime}-\mathbf{D}^{\prime}$ At 81-days old, kaolin deposits in the basal cisterns (BC) obscured the pyramids and ventriculomegaly was prominent throughout the ventricular system, including the 4 th ventricle (V4). $\mathbf{A}^{\prime \prime}-\mathbf{D}^{\prime \prime}$. Shunted animals all retained the kaolin obstruction in the basal cisterns, and in some cases (this example), the ventricles were not reduced in size and the cortex lateral to the temporal horn (LVt) remained thin. The ventricular catheter contacted the choroid plexus (CP) but retained some open drainage holes, and a portion the catheter track (black arrow in D") penetrated the fimbria. $\mathrm{H}$-hippocampus. Scale bars-10 $\mathrm{mm}$

(i.e., olfactory, lateral, 3rd, and 4th ventricles; Figs. 46). Quantification of ventricular volume confirmed the extent and variability of ventriculomegaly (Fig. 5). Ventricular volume increased significantly $(\mathrm{p}<0.001)$ in all ventricles compared to both intact and sham controls. Regional variations existed within the cerebral ventricles; proportionally, the lateral ventricles expanded the most, followed by the 4th ventricle. All 17 untreated cases (no-shunt or pre-shunt) exhibited lateral and total ventricular volumes that were above 2 standard deviations from the sham control mean. We arbitrarily set this threshold to determine which cases were "hydrocephalic". Linear regression revealed highly significant correlations between lateral ventricular volume and olfactory, third, and fourth ventricle volumes (Fig. 6).

\section{Post-induction neurological and cognitive outcomes}

For about 24-hours following kaolin injections and recovery, pigs were mildly lethargic with most of the cases exhibiting increases in body temperature (103.5$108.0{ }^{\circ} \mathrm{C}$; normal $=100.5-103.5{ }^{\circ} \mathrm{C}$ ) and some showed mild ataxia (imbalance, wider stance, stretching of hindlimbs). When this acute response occurred, it usually was resolved within 2-3 days with appropriate medical management (Buprenorphine/Buprenex, Tylenol suppository, Carprofen/Rimadyl, Baytril, and Dexamethasone) and with occasional alcohol baths for hyperthermia. Past 2-3 days post-kaolin, these animals did not exhibit any signs of pain or discomfort, and were alert with normal reflexes, consumed food and water, and gained weight throughout the post-kaolin period. Nevertheless, 

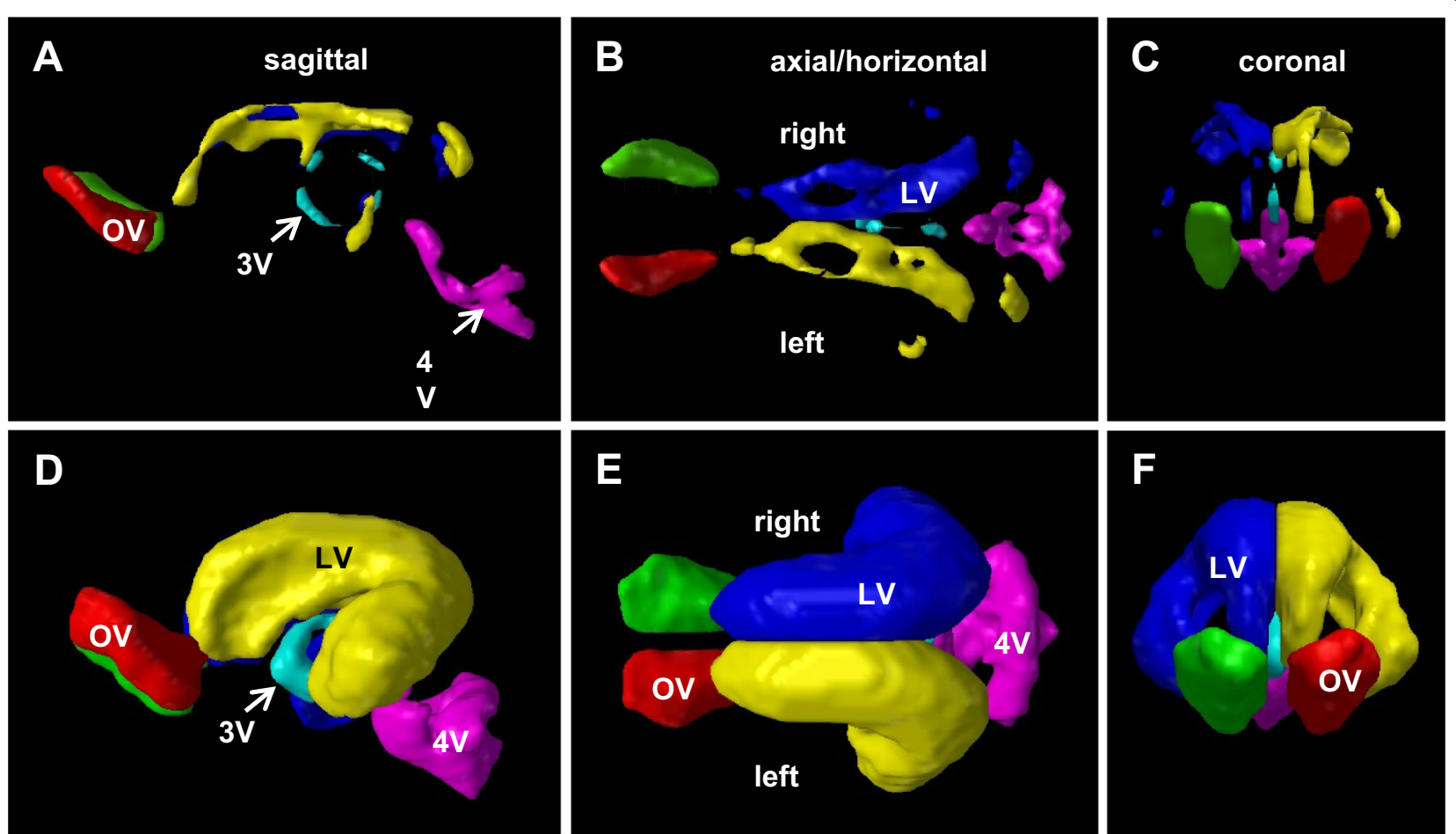

Fig. 4 Ventricular volume reconstructions of representative age-matched sham control (A-C) and untreated hydrocephalic pigs (D-E). Note the CSF-filled olfactory ventricles (OV) in normal animals and the dramatic expansion of all cerebral ventricles following intracisternal kaolin injections. Total ventricular volumes were $1906 \mathrm{~mm}^{3}$ and $21,778 \mathrm{~mm}^{3}$ for the sham (case 23) and untreated hydrocephalic (case 16, post-induction MRI), respectively

neuroimaging revealed ventriculomegaly in most of these animals (see Additional file 3: Figure S3).

Preliminary results from cognitive testing (Additional file 4: Figure S4 showed a non-significant trend toward a higher Recognition Index and significantly more exploratory time $(\mathrm{p}=0.008)$ in the post-induction animals compared to normal (pre-induction) pigs, suggesting possible learning impairment; i.e., more time was needed to become familiar with the novel object.

\section{Post-shunt results-catheter placement and ventriculomegaly}

Although neuroimaging was not performed on all 8 shunted cases due to logistics, available post-shunt scans revealed optimal $(\mathrm{n}=2)$ and sub-optimal $(\mathrm{n}=2)$ shunt placements. In cases 13 and 17 with optimal shunt placement, ventriculomegaly was reduced (Fig. 7A-C. In the suboptimal shunt cases 10 and 12 the proximal portion of the ventricular catheter was deeply embedded in periventricular tissue (Fig $7 D^{\prime}-F^{\prime \prime}$ ) and ventriculomegaly increased.. In pilot studies, while attempting different trajectories (including coronal), gross anatomy revealed that the tip of the catheter occasionally penetrated the head of the caudate nucleus, the thalamus, the hippocampus, or the periventricular white matter. Subsequently, when the insertion of the catheter was limited to $3.5 \mathrm{~cm}$ from the external surface of the occipital skull to the approximate location of the foramen of Monro, more consistent and optimal placement within the lateral ventricle was achieved (Fig. 7), with the drainage holes open to CSF. In many cases, at least a portion of the catheter contacted the ventricular wall or the choroid plexus (sub-optimal placement, Fig. 7). Contact with the choroid plexus was occasionally associated with hemorrhage throughout this structure, and in these cases, blood was present in the distal valve and catheter. On two occasions, the plastic anchor, which had been sutured to the occipital bone and the catheter as it exited the skull, had become detached. This detachment allowed the ventricular catheter to migrate superficially, in one case dorsally into the parietal and occipital cerebral cortex; in the other case, the catheter had exited the cranial cavity and the proximal tip was located within the cervical musculature. Importantly, because both of these sub-optimal cases were 

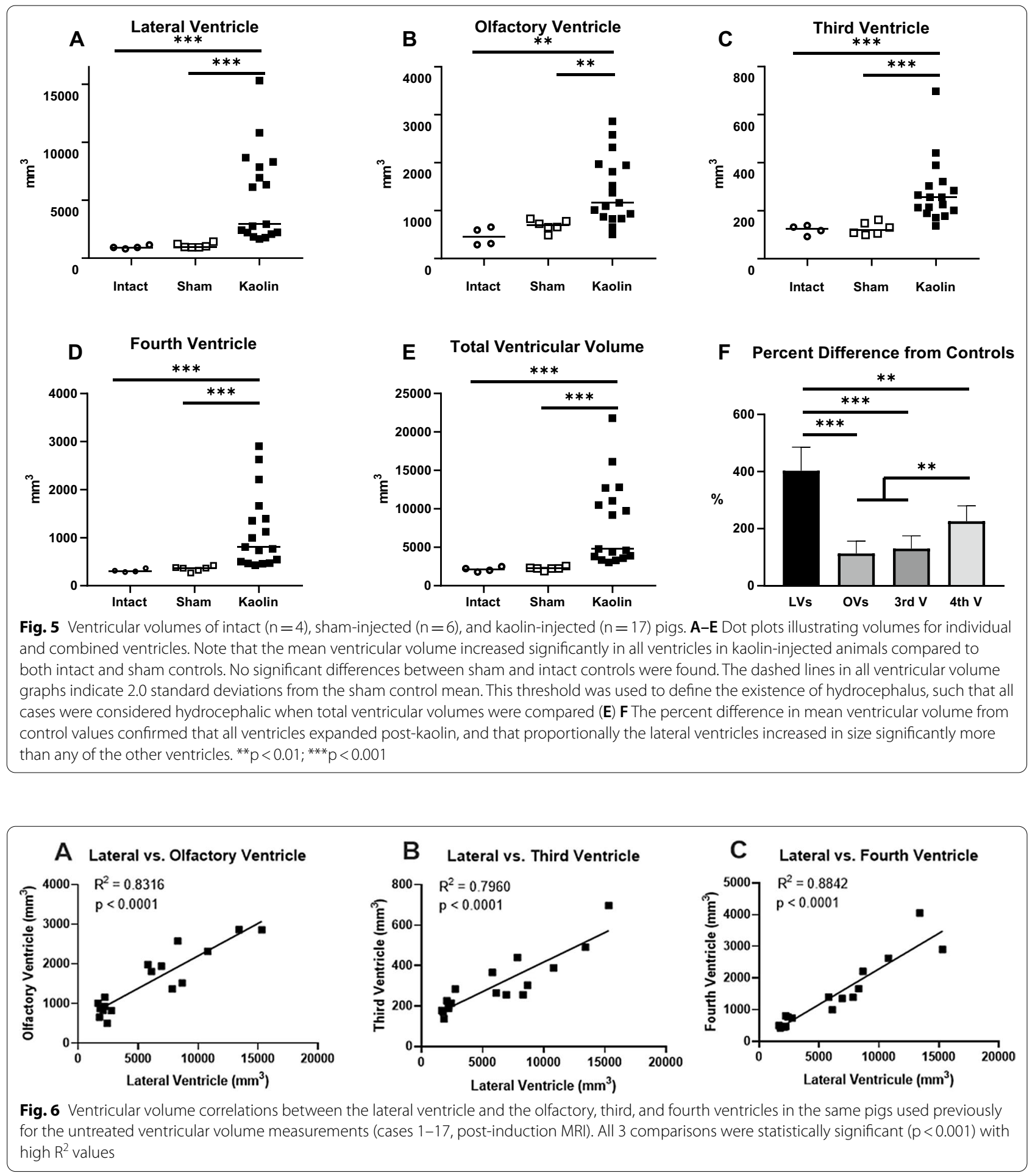

asymptomatic for the entire 30-day post-shunt survival period, it is likely that CSF drainage had been effective for at least a portion of the treatment period. We now use Stealth guidance to optimize the trajectory to the lateral ventricle.

\section{Post-shunt complications}

The most prevalent complication was sub-optimal placement of the ventricular catheter, especially in the initial cases. It was difficult to sense tissue penetration as the 
catheter was advanced (sub-optimal shunt placement, Fig. 7); therefore, it was necessary to rely on the preshunt MRI for trajectory planning. As we gained experience, several parameters became very important for optimal placement of the ventricular catheter: (1) The dorsoventral 'height' of the lateral ventricle should be at least $6.0 \mathrm{~mm}$ for a standard catheter with an outside diameter of $2.3 \mathrm{~mm}$; we were most successful when this dimension was $10-13 \mathrm{~mm}$. (2) Insertion should be no more than $3.5 \mathrm{~cm}$ from the surface of the occipital bone; this placed the proximal tip of the catheter near the foramen of Monro and prevented penetration of the caudate nucleus. (3) Insertion should be parallel to the dorsal surface of the skull; the tendency to advance perpendicular to the face of the occipital bone caused the catheter to be angled inferiorly with penetration of the thalamus, caudate nucleus, and/or hippocampus. (4) A plastic anchor, screwed into the occipital bone, should be used to secure the ventricular catheter in place; the Medtronic anchor supplied with standard catheters was ideal for this purpose.

Post-shunt periods less than 28 days were characterized by relatively acute onset of neurological symptoms $(n=4 / 8$, cases 11-14); often demise began $6-24$ h before euthanasia was required, and in two cases animals that appeared normal developed profound seizures just 8-10 h later. Shunt patency studies were not performed in vivo, so it is not possible to know unequivocally if these cases represented shunt malfunction. No shunted animals became febrile or developed infections.

\section{Discussion}

This report demonstrates that percutaneous injections of kaolin frequently produce significant moderate to severe bilateral ventriculomegaly in all cerebral ventricles, including the olfactory ventricle, which in pigs is patent normally but expands further during hydrocephalus. Conspicuous CSF flow voids were also observed in the third ventricle, foramina of Monro, and cerebral aqueduct. Kaolin deposits were primarily confined to the basal cisterns where they formed a solid cast that encased the subarachnoid arteries and veins; although kaolin injections were targeted to the cisterna magna and clear CSF was obtained prior to injection, this portion of the subarachnoid space was patent. Because pigs do not have a foramen of Magendie [100, 101] ; kaolin within the cerebellopontine angle may block the foramina of Luschka and be sufficient to cause marked enlargement of the 4th ventricle. Most untreated pigs with ventriculomegaly remained asymptomatic for relatively long postinduction periods, although preliminary novel object recognition tests revealed cognitive changes. Ventriculoperitoneal shunting was possible, with complications suggestive of shunt failure occurring in about half of these cases.

The development of this model builds on previous work in several gyrencephalic animals, some of which represent maturing infantile and juvenile brains. Many studies of normal and altered CSF physiology and ICP have been performed on felines, canines, and non-human primates, and the data produced by these experiments have provided the foundation for the current understanding of CSF and ICP biomechanics. More recent experiments in hydrocephalic kittens and dogs have revealed the cytopathology commonly produced by ventriculomegaly [23, $44,45,49-51,53,57,58,102,103]$ and the importance of CSF pulsatility [104-108]. Continued studies on these species have been thwarted by societal concerns for the well-being of these animals, and many institutions are reluctant to permit chronic survival experiments in these hydrocephalic models; the studies that have continued have become highly regulated and expensive. Nevertheless, FDA approval of new therapeutic devices and sensors often requires pre-clinical proof of biocompatibility and efficacy in animal models that are large enough to accommodate clinical devices; this is especially true for novel approaches that seek to improve shunt technology. The need for more translational in vivo models

\footnotetext{
(See figure on next page.)

Fig. 7 Representative optimal and sub-optimal shunt placements in hydrocephalic pigs after 20-30 days of treatment. A-F'. T2-weighted sagittal, axial, and coronal MRl images illustrating optimal (case 13, A-C') and sub-optimal (case 10 D-F') shunt placement. Pre- and post-shunt images were taken from the same two pigs. Shunting reduced (but did not eliminate) the flow void in the third ventricle and decreased the size of all ventricles when optimally placed, but not to control levels. In the optimal case, the arrows indicate the catheter $\left(\mathbf{A}^{\prime}-\mathbf{C}^{\prime}\right)$ inside of the right lateral ventricle. In the sub-optimal case $\left(\mathbf{D}^{\prime}-\mathbf{F}^{\prime}\right)$, arrows indicate the catheter and asterisks indicate the catheter tip $\left(\mathbf{D}^{\prime}-\mathbf{F}^{\prime}\right)$. $\mathbf{G}-\mathbf{L}$ Representative gross morphological features of shunt-treated hydrocephalic pig brains (Case 13 for optimal placement, and Case 12 for sub-optimal case). In sub-optimal case, the catheter (arrow in $\mathbf{J}$ ) was located along the dorsolateral wall of the lateral ventricle with some contact with the choroid plexus. In all cases, $\mathbf{H}$ and $\mathbf{I}, \mathbf{K}$ and $\mathbf{L}$ columns contain coronal views from the same case as the midsagittal sections in $\mathbf{G}$ and $\mathbf{J}$, respectively. In the optimally placed shunt case, the ventricles were reduced in size but not in the sub-optimal placement. In $\mathbf{J}$ and $\mathbf{L}$, the ventricular catheter contacted the choroid plexus (CP) but retained some open drainage holes, and the catheter track (black arrow in $\mathbf{J}$ and $\mathbf{L}$ ) contacted the CP. $\mathbf{M}$ Graph showing the total ventricular volumes in $\mathrm{mm}^{3}$ before (pre) and after (post) 20-30 days of shunt treatment (Sub-optimal cases are case 10 -blue- and case 12-red-; optimal cases are 13-green- and 17 -purple-). $\mathbf{N}-\mathbf{P}$ Ventricular volume reconstructions of a representative optimal shunt placement before and after shunt treatment in the same cases used for the MRI (case 13). Note the reduction of the total ventricular volume after 30 days of shunt treatment. Abbreviations: a, anterior, I, left, p, posterior, r, right. Scale bars $=10 \mathrm{~mm}$ for all the MRI scan and gross anatomy panels
} 


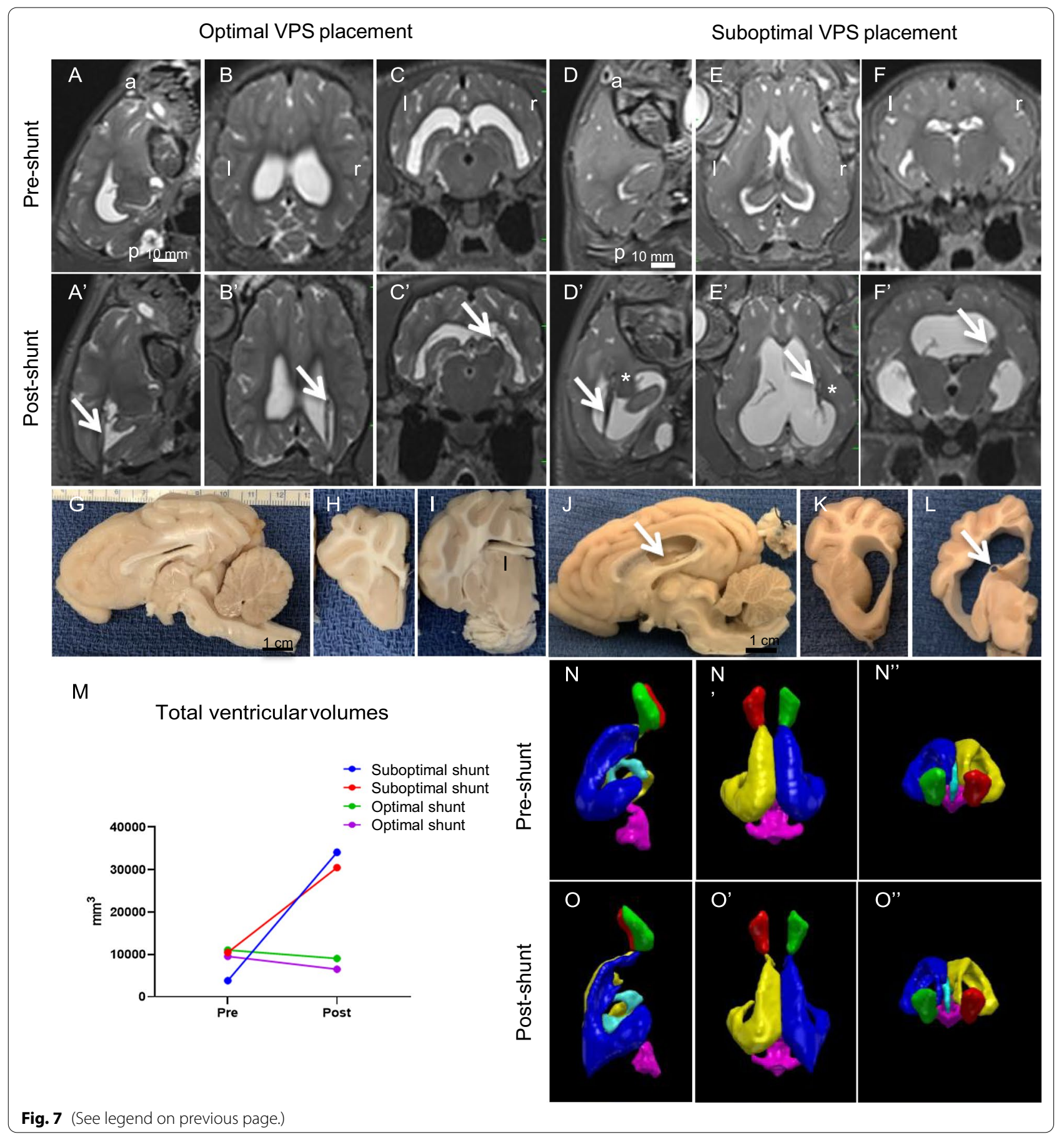

has been recognized by the NIH in their small business incentive programs and promoted by the Hydrocephalus Association, which helped produce an important white paper emphasizing the inclusion of large animal models in experimental studies [13, 14, 109]. Importantly, because of the chronic nature of hydrocephalus and the need for long-term treatments, this model needs further development in terms of the growth of these animals (i.e., the need to lengthen the distal catheter), progressive ventriculomegaly in untreated animals, and the impact of repetitive shunt malfunctions.

It is worth noting that porcine species normally have a somewhat unique CSF-filled chamber within large olfactory bulbs that communicate with the lateral ventricles. 
Absorption of CSF into the nasal lymphatics that surround the olfactory nerves as they pass through the cribriform plate was initially discovered in rabbits, cats, and non-human primates by McComb and his colleagues in 1975 [110-112]. More recently, Johnston et al. have shown conclusively that this CSF outflow pathway exists in a variety of species, including humans, and have promoted the notion that nasal lymphatics could at least provide an alternative CSF absorption route when other pathways are obstructed [113-119]. This pathway could conceivably be a functional mechanism for relieving CSF pressure in our pig model, thereby allowing long symptom-free durations.

Post-induction ventriculomegaly was variable in our cases and did not appear to be correlated with the extent of kaolin obstruction or the post-kaolin duration. However, there was a strong correlation between lateral ventricle and olfactory ventricle size. While the variation in ventricular volume amongst cases highlights the need to use neuroimaging to confirm ventriculomegaly, it is worth noting that similar variations occur clinically in patients with hydrocephalus and that ventriculomegaly is not predictive of outcome unless it is quite severe [120124]. To define "hydrocephalus" consistently, we applied thresholds of 1.0 and 2.0 standard deviations from the sham control mean ventricular volumes to the postkaolin cases. This approach demonstrated that all cases were considered "hydrocephalic" when the mean lateral ventricular volumes and the combined lateral and olfactory ventricle volume were above 2.0 standard deviations from controls. We recommend that this approach be used in other experimental studies to standardize different types of hydrocephalus [125]. Unfortunately, we did not have enough intermediate MRI time points during the post-kaolin to pre-shunt period to show age-related progressive changes in ventriculomegaly.

Neurological deficits and signs of pain or discomfort were primarily confined to the immediate post-induction period and at the onset of shunt malfunction. In vivo neuroimaging and gross morphological observations confirmed that the intracisternal kaolin injections consistently produced large casts that completely blocked the basal cisterns. Increased body temperature almost always occurred 3-24 h post-kaolin, and while it could be controlled with medications such as Tylenol, Rimadyl (Carprofen), and Dexamethasone, it seemed highly predictive of a successful kaolin injection. Other behavioral and neurological signs, such as mild ataxia, lethargy, loss of appetite, head tilt, and coarse hair coat abated within 1-2 days post-induction, and most animals remained symptom-free for 1-4 weeks. These signs and symptoms returned, however, in 4 of 8 shunted animals within 5-20 days post-shunt. Usually, these behavioral changes were gradual enough to allow neuroimaging and collection of tissue before the shunt malfunction caused further demise, but it was not uncommon for rapid deterioration to occur. The contrast between untreated animals with no signs or symptoms for 14-43 days post-kaolin and these shunted cases suggests that shunt malfunctions may have been responsible for the early demise; an alternative possibility is that animals with the largest ventricles were chosen for shunt treatments to optimize the feasibility of the surgery.

The ability to reduce ventriculomegaly with shunting in an in vivo model is encouraging. Although further improvements could be made for optimal and consistent placement of the ventricular catheter, most notably with the aid of neuronavigation, shunting can be performed successfully with clinical drainage systems. It is worth noting that our occipital approach placed the ventricular catheter close to the choroid plexus, an issue which has prompted many neurosurgeons to favor a frontal approach in the treatment of children. We are currently exploring a frontal approach in which the ventricular catheter is inserted orthogonally into the frontal horn of the lateral ventricle. Access to a distal reservoir also allows serial taps for CSF samples for subjective assessments of shunt function and evaluation of CSF biomarkers. In addition to permitting experimental studies of the effects of shunt timing on pathophysiology, this model allows systematic evaluations of novel shunt designs. For example, several of our ongoing studies with this model involve biocompatibility (i.e., safety) evaluations, efficacy of new catheter materials and designs, and tests of CSF flow detection monitors. Intraoperative guidance, when available, should improve the placement of ventricular shunt catheters. Furthermore, our preliminary experience with neuroendoscopic procedures, specifically ETV and ETV-CPC, demonstrates that these treatment options can be explored systematically and produce promising results in this model. A study detailing ETV and ETV-CPC in this model is forthcoming.

In Conclusion, kaolin injections into the cisternal magna of juvenile pigs produced significant bilateral ventriculomegaly in all regions of the cerebral ventricles in approximately $85 \%$ of cases, with kaolin deposits and arachnoiditis forming a substantial obstruction in the basal cisterns. The cisterna magna was patent and enlarged and a thin membrane separated it from the posterior wall of the 4th ventricle. A few animals required a second kaolin injection to produce ventriculomegaly. Ventricular volume data suggested that a threshold of 2 standard deviations above the mean value for sham controls could be considered as the defining point for classifying cases as "hydrocephalic". Untreated pigs were asymptomatic for up to 43 days post-induction. 
Commercially-available ventriculoperitoneal shunts were placed successfully in hydrocephalic animals. These shunts, if patent, remained functional for 30-50 days. However, if tissue and blood obstructed the ventricular catheter or the distal valve, shunt failure occurred at 3-21 days post-shunt. Preliminary cognitive tests designed specifically for pigs suggested that untreated hydrocephalic pigs spent more time exploring novel objects. This reliable model of acquired juvenile hydrocephalus is highly translational, allowing for systematic studies of the pathophysiology and clinical treatment of hydrocephalus.

\section{Supplementary Information}

The online version contains supplementary material available at https://doi. org/10.1186/s12987-021-00281-0.

Additional file 1: Fig.S1. Representative T2-weighted MRI images summarizing brain and ventricular morphology in non-hydrocephalic control $(\mathbf{A}-\mathbf{F})$, hydrocephalic just prior to shunting $\left(\mathbf{A}^{\prime}-\mathbf{F}^{\prime}\right)$, and post-shunt $\left(\mathbf{A}^{\prime \prime}-\mathbf{F}^{\prime \prime}\right)$ piglets. The intact control piglet (case 25$)$ is 41-days old. Pre- and post-shunt images are taken from the same piglet (case 13 at 18-days post-kaolin and 30-days post-shunt, respectively. $\left(\mathbf{A}^{\prime}-\mathbf{F}^{\prime}\right)$ In the pre-shunt condition, note the prominent flow void (FV, black profile) within the third ventricle and cerebral aqueduct ( $\mathbf{A}^{\prime}$ ) indicative of high CSF pulsatility, the black signal indicating kaolin blockage of the basal cisterns ( $B C$ in $\mathbf{B}^{\prime}$ ), the patent channel connecting the olfactory ventricle $(\mathrm{OV})$ to the lateral ventricle (LV), the choroid plexus (CP) floating in the $\mathrm{LV}\left(\mathbf{C}^{\prime}\right)$, and the enlargement of all cerebral ventricles, especially the temporal horns (TH) containing the hippocampus $(H)$. The cisterna magna $(C M)$ remains open. $\left(\mathbf{A}^{\prime \prime}-\mathbf{F}^{\prime \prime}\right)$ Shunting reduced (but did not eliminate) the flow void in the third ventricle $\left(\mathbf{A}^{\prime \prime}\right)$ and decreased the size of all ventricles, but not to normal levels. In this case, the catheter ( $D^{\prime \prime}$, arrows indicate brain entry and the catheter located along the dorsal wall of the LV with some contact with the choroid plexus. Scale bars $=10 \mathrm{~mm}$ for all panels.

Additional file 2: Fig. S2. Representative T2-weighted coronal images summarizing brain and ventricular morphology in non-hydrocephalic control (A-J) and hydrocephalic pre-shunt $\left(A^{\prime}-J\right)$ pigs; panels arranged left to right from anterior to posterior and matched to corresponding levels (i.e. A and $A^{\prime}$ ). Pre-shunt images are taken from case 13 at 18-days post-kaolin. The control pig (case 25) is 41-days old. In the hydrocephalic pre-shunt condition, note the enlargement of all cerebral ventricles and the cisterna magna (CM), prominent flow voids (black) within the third ventricle $\left(3, E^{\prime}\right)$ indicative of high CSF pulsatility, the large olfactory ventricles (OV), and the choroid plexus (CP) in the lateral ventricle LV, and the kaolin (black) blockage of the basal cisterns (BC) and foramina of Luschka (FL). 4 - fourth ventricle, $\mathrm{H}$ - hippocampus, $\mathrm{FH}$ - frontal horn, FM - foramen of Monro, $\mathrm{OH}$ - occipital horn, $\mathrm{TH}$ - temporal horn. Scale bar $=10 \mathrm{~mm}$ for all panels.

Additional file 3: Fig.S3. Representative T2-weighted axial MRI images summarizing brain and ventricular morphology in non-hydrocephalic control (A-E) and hydrocephalic just prior to shunting ( $\left.A^{\prime}-E^{\prime}\right)$ pigs. The control pig (case 25) is 41-days old. Pre- shunt images are taken from pig case 13 at 18-days post-kaolin. In the pre-shunt condition, note the enlargement of all cerebral ventricles and the cisterna magna (CM), prominent flow voids (black) within the foramina of Monro (in $C^{\prime}$ ) and third ventricle/ cerebral aqueduct (in $C^{\prime}$ and $D^{\prime}$ ) indicative of high CSF pulsatility, the patent channel connecting the olfactory ventricle (OV) to the lateral ventricle $(\mathrm{LV})$, and the choroid plexus (CP) floating in the LV. LVt - temporal horn of the lateral ventricle. Scale bar $=10 \mathrm{~mm}$ for all panels.

Additional file 4: Fig.S4. Real-time video segment of a typical cognitive test. Initially, during the habituation phases, the same 2 objects are available for the pig to explore. After a rest day, the same pig is tested again with one of the previous "familiar" objects (the rectangular pan) and a novel object (the round pan). The time spent exploring each object is recorded. In this case, the animal spent more time exploring the novel object, indicating that it has remembered the familiar object. Cognitively impaired animals will spend disproportionately more time exploring the initial, presumably familiar, object $[96,97]$.

Additional file 5: Table S1. Medications.

\section{Acknowledgements}

We are sincerely grateful for all the veterinary and surgical support provided by the staff in the Division of Comparative Medicine at the Washington University School of Medicine, namely Charles Mitchell, Angela Lewis, Susan Spiess, Alicia Sexauer, Julie Long, Troy Ingram, Amanda Fears, Zach Wellborn, Ken Smith, and Robin Mueller. Linda Hood, Facility Manager \& MRI Technologist, Department of Radiology-Research Entities, and Wilnellys Moore, MRI Technologist, were invaluable in scheduling and performing the MRI scans.

\section{Authors' contributions}

JPM helped conceive and directed the study, obtained funding, performed or assisted in all animal procedures, assisted data collection and analyses, wrote and maintained animal protocols, and wrote and directed the manuscript. MRT helped conceive the study, performed or assisted in all animal procedures, edited animal protocols and edited the manuscript. AMI helped conceive the study, provided advice on the experimental design, performed or assisted in all animal procedures and data analyses, and edited the manuscript. SHZ and MG-B provided advice on the experimental design, performed or assisted in most of the animal procedures and data analyses, especially the cognitive testing, and extensively edited the manuscript. LC-R helped conceive the study, assisted in all animal procedures, and edited the manuscript. ALH analyzed MRI data and edited the manuscript. RND and SAF designed the cognitive testing experiments, analyzed data, and edited the manuscript. RKG helped design the cognitive testing, analyze data, and edited the manuscript. DMM provided advice on the experimental design, assisted in data analyses, and edited the manuscript. CAH provided advice on all aspects of the study, especially shunting experiments, and edited the manuscript. DDL conceived the study, obtained funding, performed or assisted in all surgical treatment procedures, assisted data collection and analyses, and edited the manuscript. All authors read and approved the final manuscript.

\section{Funding}

This work was supported in part by NIH 5R21NS111249-02, Microbot Medical, Inc., Medtronic Neurosurgery, and Karl Storz Endoscopy-America, Inc. to JPM and DDL.

Availability of data and materials

All data generated or analyzed during this study are included in this published article and its Additional files.

\section{Declarations}

Ethics approval and consent to participate

No human subjects or tissue.

\section{Consent for publication}

Not applicable.

\section{Competing interests}

No competing interests to declare.

\section{Author details}

${ }^{1}$ Department of Neurosurgery, Washington University in St. Louis School of Medicine, St. Louis, MO 63110, USA. ²Division of Comparative Medicine, Washington University in St. Louis School of Medicine, St. Louis, MO 63110, USA. ${ }^{3}$ Department of Surgery, Division of Neurosurgery, University of Calgary School of Medicine, Calgary, AB T2N 2T9, Canada. ${ }^{4}$ Department of Animal Sciences, Division of Nutritional Sciences, Neuroscience Program, University of Illinois, Champagne-Urbana, Illinois 61801, USA. ${ }^{5}$ Traverse Science, Champaign, 
IL 61801, USA. ${ }^{6}$ Department of Chemical Engineering and Materials Science, Wayne State University, Detroit, Ml 48202 , USA. ${ }^{7}$ Department of Neurosurgery, Wayne State University School of Medicine, Detroit, MI 48202, USA. ${ }^{8}$ Department of Pediatrics, St. Louis Children's Hospital, St. Louis, MO 63110, USA. ${ }^{9}$ Department of Neurosurgery, BJC Institute of Health, 425 S. Euclid, Campus, Box 8057, St. Louis, MO 63143, USA.

Received: 16 April 2021 Accepted: 9 October 2021

Published online: 08 November 2021

\section{References}

1. Vinchon M, Rekate H, Kulkarni AV. Pediatric hydrocephalus outcomes: a review. Fluids Barriers CNS. 2012;9(1):18.

2. Dewan MC, Rattani A, Mekary R, et al. Global hydrocephalus epidemiology and incidence: systematic review and meta-analysis. J Neurosurg. 2019;103:1065-79.

3. Robinson S. Neonatal posthemorrhagic hydrocephalus from prematurity: pathophysiology and current treatment concepts. J Neurosurg Pediatr. 2012;9(3):242-58.

4. Pyykko OT, Nerg O, Niskasaari HM, et al. Incidence, comorbidities, and mortality in idiopathic normal pressure hydrocephalus. World Neurosurg. 2018;112:e624-31.

5. Isaacs AM, Williams MA, Hamilton MG. Current update on treatment strategies for idiopathic normal pressure hydrocephalus. Curr Treat Options Neurol. 2019;21(12):65.

6. Tisell M, Hoglund M, Wikkelso C. National and regional incidence of surgery for adult hydrocephalus in Sweden. Acta Neurol Scand. 2005;112(2):72-5.

7. Sharkey P, Monsalve GP, Rigamonti A, et al. Healthcare expenditures of medicare beneficiaries with normal pressure hydrocephalus. World Neurosurg. 2019;127:e548-55.

8. Dorner RA, Allen MC, Robinson S, et al. Early neurodevelopmental outcome in preterm posthemorrhagic ventricular dilatation and hydrocephalus: Neonatal ICU Network Neurobehavioral Scale and imaging predict 3-6-month motor quotients and Capute Scales. J Neurosurg Pediatr. 2019;25:217-27.

9. Vinchon M, Baroncini M, Delestret I. Adult outcome of pediatric hydrocephalus. Childs Nerv Syst. 2012;28(6):847-54.

10. McGirt MJ, Woodworth G, Coon AL, Thomas G, Williams MA, Rigamonti D. Diagnosis, treatment, and analysis of long-term outcomes in idiopathic normal-pressure hydrocephalus. Neurosurgery. 2008;62(Suppl 2):670-7.

11. Schmidt LB, Corn G, Wohlfahrt J, Melbye M, Munch TN. School performance in children with infantile hydrocephalus: a nationwide cohort study. Clin Epidemiol. 2018;10:1721-31.

12. Iglesias S, Ros B, Martin A, Carrasco A, Rius F, Arraez MA. Functional outcome in pediatric hydrocephalus: results of applying the Spanish version of the Hydrocephalus Outcome Questionnaire. J Neurosurg Pediatr. 2018:21(3):224-35.

13. McAllister JP, Williams MA, Walker ML, et al. An update on research priorities in hydrocephalus: overview of the third National Institutes of Health-sponsored symposium "Opportunities for Hydrocephalus Research: Pathways to Better Outcomes." J Neurosurg. 2015;123(6):1163-6.

14. Koschnitzky JE, Keep RF, Limbrick DD Jr, et al. Opportunities in posthemorrhagic hydrocephalus research: outcomes of the Hydrocephalus Association Posthemorrhagic Hydrocephalus Workshop. Fluids Barrier CNS. 2018;15(1):11.

15. Vink R. Large animal models of traumatic brain injury. J Neurosci Res. 2018:96(4):527-35.

16. Vink R, Bullock MR. Traumatic brain injury: therapeutic challenges and new directions. Neurotherapeutrics. 2010;7(1):1-2.

17. Rosenfeld JV, Maas Al, Bragge P, Morganti-Kossmann MC, Manley GT, Gruen RL. Early management of severe traumatic brain injury. Lancet. 2012;380(9847):1088-98.
18. Aoyama Y, Kinoshita Y, Yokota A, Hamada T. Neuronal damage in hydrocephalus and its restoration by shunt insertion in experimental hydrocephalus: a study involving the neurofilament-immunostaining method. J Neurosurg Pediatr. 2006;104:332-9.

19. Castro ME, Portnoy HD, Maesaka J. Elevated cortical venous pressure in hydrocephalus. Neurosurgery. 1991;29(2):232-8.

20. DeFeo DR, Myers P, Foltz E, Everett B, Ramshaw B. Histological examination of kaolin-induced hydrocephalus. J Neurosurg. 1979;50:70-4.

21. Deo-Narine V, Gomez DG, Vullo T, et al. Direct in vivo observation of transventricular absorption in the hydrocephalic dog using magnetic resonance imaging. Invest Radiol. 1994;29(3):287-93.

22. Dohrmann GJ. The choroid plexus in experimental hydrocephalus. A light and electron microscopic study in normal, hydrocephalic, and shunted hydrocephalic dogs. J Neurosurg. 1971;34:56-69.

23. Dombrowski SM, Deshpande A, Dingwall C, Leichliter A, Leibson Z, Luciano MG. Chronic hydrocephalus-induced hypoxia: increased expression of VEGFR-2+ and blood vessel density in hippocampus. Neuroscience. 2008;152(2):346-59.

24. Drake JM, Potts DG, Lemaire C. Magnetic resonance imaging of silasticinduced canine hydrocephalus. Surg Neurol. 1989;31:28-40.

25. Fishman RA, Greer M. Experimental obstructive hydrocephalus. Changes in the cerebrum. Arch Neurol. 1963;8:156-61.

26. Fukuhara T, Luciano MG, Brant CL, Klauscie J. Effects of ventriculoperitoneal shunt removal on cerebral oxygenation and brain compliance in chronic obstructive hydrocephalus. J Neurosurg. 2001;94(4):573-81.

27. Hochwald GM, Sahar A, Sadik AR, Ransohoff J. Cerebrospinal fluid production and histological observations in animals with experimental obstructive hydrocephalus. Exp Neurol. 1969;25:190-9.

28. James AE Jr, Burns B, Flor WF, et al. Pathophysiology of chronic communicating hydrocephalus in dogs (Canis familiaris). Experimental studies. J Neurol Sci. 1975:24(2):151-78.

29. Johnson MJ, Ayzman I, Wood AS, et al. Development and characterization of an adult model of obstructive hydrocephalus. J Neurosci Methods. 1999;91(1-2):55-65.

30. Kolecka M, Ondreka N, Moritz A, Kramer M, Schmidt MJ. Effect of acetazolamide and subsequent ventriculo-peritoneal shunting on clinical signs and ventricular volumes in dogs with internal hydrocephalus. Acta Vet Scand. 2015;57:49.

31. Park EH, Eide PK, Zurakowski D, Madsen JR. Impaired pulsation absorber mechanism in idiopathic normal pressure hydrocephalus: laboratory investigation. J Neurosurg. 2012;117(6):1189-96.

32. Penn RD, Lee MC, Linninger AA, Miesel K, Lu SN, Stylos L. Pressure gradients in the brain in an experimental model of hydrocephalus. $J$ Neurosurg. 2005;102(6):1069-75.

33. Pinto FC, Becco R, Alho EJ, et al. The retrograde ventriculosinusal shunt in an animal experimental model of hydrocephalus. Pediatr Neurosurg. 2016:51(3):142-8.

34. Portnoy HD, Branch C, Castro ME. The relationship of intracranial venous pressure to hydrocephalus. Childs Nerv Syst. 1994;10(1):29-35.

35. Rekate H, Olivero W, McCormick J, Chizeck H, Ko W. Resistance elements within the cerebrospinal fluid circulation. Outflow Cerebrospinal Fluid Alfred Benzon Symp. 1989;27:45-52.

36. Sahar A, Hochwald GM, Kay WJ, Ransohoff J. Spontaneous canine hydrocephalus: cerebrospinal fluid dynamics. J Neurol Neurosurg Psychiatry. 1971;34(3):308-15.

37. Schmidt MJ, Rummel C, Hauer J, et al. Increased CSF aquaporin-4, and interleukin-6 levels in dogs with idiopathic communicating internal hydrocephalus and a decrease after ventriculo-peritoneal shunting. Fluids Barr CNS. 2016;13(1):12.

38. Wagshul ME, Kelly EJ, Yu HJ, Garlick B, Zimmerman T, Egnor MR. Resonant and notch behavior in intracranial pressure dynamics. J Neurosurg Pediatr. 2009;3(5):354-64.

39. Wisniewski H, Weller RO, Terry RD. Experimental hydrocephalus produced by the subarachnoid infusion of silicone oil. J Neurosurg. 1969;31:10-4

40. Higashi K, Noda Y, Tachibana S. Study of brain tissue impedance in the hydrocephalic cat. J Neurol Neurosurg Psychiatry. 1989;52(5):636-42.

41. da Silva MC, Michowicz S, Drake JM, Chumas PD, Tuor UI. Reduced local cerebral blood flow in periventricular white matter in experimental 
neonatal hydrocephalus-restoration with CSF shunting. J Cereb Blood Flow Metabol. 1995;15(6):1057-65.

42. Del Bigio MR, da Silva MC, Drake JM, Tuor UI. Acute and chronic cerebral white matter damage in neonatal hydrocephalus. Can J Neurol Sci. 1994;21(4):299-305.

43. Lovely TJ, Miller DW, McAllister JP 2nd. A technique for placing ventriculoperitoneal shunts in a neonatal model of hydrocephalus. J Neurosci Methods. 1989;29(3):201-6.

44. Wright LC, MCAllister JP 2nd, Katz SD, et al. Cytological and cytoarchitectural changes in the feline cerebral cortex during experimental infantile hydrocephalus. Pediatr Neurosurg. 1990;16(3):139-55.

45. McAllister JP 2nd, Cohen Ml, O'Mara KA, Johnson MH. Progression of experimental infantile hydrocephalus and effects of ventriculoperitoneal shunts: an analysis correlating magnetic resonance imaging with gross morphology. Neurosurgery. 1991;29(3):329-40.

46. Hale PM, McAllister JP 2nd, Katz SD, et al. Improvement of cortical morphology in infantile hydrocephalic animals after ventriculoperitoneal shunt placement. Neurosurgery. 1992;31(6):1085-96.

47. Williamson EC, Pearson HE, McAllister JPI. Gliosis and ganglion cell death in the developing cat retina during hydrocephalus and after decompression. Dev Brain Res. 1992;70(1):47-52.

48. Kriebel RM, Shah AB, McAllister JP 2nd. The microstructure of cortical neuropil before and after decompression in experimental infantile hydrocephalus. Exp Neurol. 1993;119(1):89-98.

49. Kriebel RM, McAllister JP 2nd. Pathology of the hippocampus in experimental feline infantile hydrocephalus. Neurol Res. 2000;22(1):29-36.

50. Eskandari R, McAllister JP 2nd, Miller JM, et al. Effects of hydrocephalus and ventriculoperitoneal shunt therapy on afferent and efferent connections in the feline sensorimotor cortex. J Neurosurg. 2004;101 (2 Suppl):196-210.

51. Eskandari R, Harris CA, McAllister JP 2nd. Reactive astrocytosis in feline neonatal hydrocephalus: acute, chronic, and shunt-induced changes. Childs Nerv Syst. 2011;27(12):2067-76.

52. Eskandari R, Packer M, Burdett EC, McAllister JP 2nd. Effect of delayed intermittent ventricular drainage on ventriculomegaly and neurological deficits in experimental neonatal hydrocephalus. Childs Nerv Syst. 2012;28(11):1849-61.

53. Eskandari R, Abdullah O, Mason C, Lloyd KE, Oeschle AN, McAllister JP 2nd. Differential vulnerability of white matter structures to experimental infantile hydrocephalus detected by diffusion tensor imaging. Childs Nerv Syst. 2014;30(10):1651-61.

54. Epstein F, Rubin RC, Hochwald GM. Restoration of the cortical mantle in severe feline hydrocephalus: a new laboratory model. Dev Med Child Neurol. 1974;16(6 Suppl 32):49-53.

55. Hochwald GM, Epstein F, Malhan C, Ransohoff J. The role of the skull and dura in experimental feline hydrocephalus. Dev Med Child Neurol. 1972;14:65-9.

56. Shapiro K, Takei F, Fried A, Kohn I. Experimental feline hydrocephalus. The role of biomechanical changes in ventricular enlargement in cats. J Neurosurg. 1985;63:82-7.

57. Takei F, Hirano A, Shapiro K, Kohn IJ. New ultrastructural changes of the ependyma in experimental hydrocephalus. Acta Neuropathol. 1987;73:400-2.

58. Takei F, Sato O. Morphological analysis of progressive hydrocephalus and shunt-dependent arrested hydrocephalus. An experimental study. Pediatr Neurosurg. 1995;23(5):246-53.

59. Lollis SS, Hoopes PJ, Kane S, Paulsen K, Weaver J, Roberts DW. Low-dose kaolin-induced feline hydrocephalus and feline ventriculostomy: an updated model. J Neurosurg Pediatr. 2009;4(4):383-8.

60. Di Curzio DL, Turner-Brannen E, Mao X, Del Bigio MR. Magnesium sulfate treatment for juvenile ferrets following induction of hydrocephalus with kaolin. Fluids Barr CNS. 2016;13:7.

61. Di Curzio DL, Buist RJ, Del Bigio MR. Reduced subventricular zone proliferation and white matter damage in juvenile ferrets with kaolininduced hydrocephalus. Exp Neurol. 2013;248C:112-28.

62. Margolis G, Kilham L. Hydrocephalus in hamsters, ferrets, rats, and mice following inoculations with reovirus type I. II. Pathologic studies. Lab Invest. 1969;21:189-98.

63. Johnston MG, Del Bigio MR, Drake JM, Armstrong D, Di Curzio DL, Bertrand J. Pre- and post-shunting observations in adult sheep with kaolin-induced hydrocephalus. Fluids Barr CNS. 2013;10(1):24.
64. De Keersmaecker B, Vloeberghs M, Ville Y. Fetal hydrocephalus and intrauterine cerebral ventriculoscopy: an animal model. Fetal Diag Ther. 2005;20(5):445-9.

65. Di Trapani G, Garzetti GG, La Cara A, Pentimalli LC. Congenital hydrocephalus: a new experimental model with histopathological study. Ital J Neurol Sci. 1990;1 1:567-72.

66. Edwards MS. An evaluation of the in utero neurosurgical treatment of ventriculomegaly. Clin Neurosurg. 1986;33:347-57.

67. Glick PL, Harrison MR, Halks-Miller M, et al. Correction of congenital hydrocephalus in utero II: efficacy of in utero shunting. J Pediatr Surg. 1984;19(6):870-81.

68. Nakayama DK, Harrison MR, Berger MS, Chinn DH, Halks-Miller M, Edwards MS. Correction of congenital hydrocephalus in utero I. The model: intracisternal kaolin produces hydrocephalus in fetal lambs and rhesus monkeys. J Pediatr Surg. 1983;18(4):331-8.

69. Di Rocco C, Pettorossi VE, Caldarelli M, Mancinelli R, Velardi F. Communicating hydrocephalus induced by mechanically increased amplitude of the intraventricular cerebrospinal fluid pressure: experimental studies. Exp Neurol. 1978;59(1):40-52.

70. Mayfrank L, Kim Y, Kissler J, et al. Morphological changes following experimental intraventricular haemorrhage and intraventricular fibrinoIytic treatment with recombinant tissue plasminogen activator. Acta Neuropathol. 2000;100(5):561-7.

71. De SN. A study of the changes in the brain in experimental internal hydrocephalus. J Pathol Bacteriol. 1950;62:197-208.

72. Pollay M. The function and structure of the cerebrospinal fluid outflow system. CSF Res. 2010;7:9.

73. Diggs J. Early changes in experimental hydrocephalus. Invest Radiol. 1986:21:118-21.

74. Michejda M, Hodgen GD. In utero diagnosis and treatment of nonhuman primate fetal skeletal anomalies. I. Hydrocephalus. JAMA. 1981;246(10):1093-7.

75. Clancy B, Kersh B, Hyde J, Darlington RB, Anand KJ, Finlay BL. Webbased method for translating neurodevelopment from laboratory species to humans. Neuroinformatics. 2007;5(1):79-94.

76. Edwards MSB, Harrison MR, Halks-Miller M, et al. Kaolin-induced congenital hydrocephalus in utero in fetal lambs and rhesus monkeys. $J$ Neurosurg. 1984;60:115-22.

77. Anderson $\mathrm{A}, \mathrm{Bij}$ Imer $\mathrm{H}$, Fournier PE, et al. Diagnosis and management of $Q$ fever-United States, 2013: recommendations from CDC and the $Q$ Fever Working Group. MMWR Recomm Rep. 2013;62(3):1-30.

78. Duncan J, Caralopoulos I, Noren G, et al. A porcine model of hydrocephalus induced by gamma knife irradiation. Cerebrospinal Fluid Res. 2009. https://doi.org/10.1186/1743-8454-6-S2-S40.

79. Aquilina K, Chakkarapani E, Thoresen M. Early deterioration of cerebrospinal fluid dynamics in a neonatal piglet model of intraventricular hemorrhage and posthemorrhagic ventricular dilation. J Neurosurg Pediatr. 2012;10(6):529-37.

80. Aquilina K, Hobbs C, Cherian S, et al. A neonatal piglet model of intraventricular hemorrhage and posthemorrhagic ventricular dilation. J Neurosurg. 2007;107(2 Suppl):126-36.

81. Mayfrank L, Kissler J, Raoofi R, et al. Ventricular dilatation in experimental intraventricular hemorrhage in pigs-characterization of cerebrospinal fluid dynamics and the effects of fibrinolytic treatment. Stroke. 1997:28:141-8.

82. Lind NM, Moustgaard A, Jelsing J, Vajta G, Cumming P, Hansen AK. The use of pigs in neuroscience: modeling brain disorders. Neurosci Biobehav Rev. 2007:31(5):728-51.

83. Pond WG, Boleman SL, Fiorotto $\mathrm{HH}$, et al. Perinatal ontogeny of brain growth in the domestic pig. Proc Soc Exp Biol Med. 2000;223:102-8.

84. Dickerson JW, Dobbing J. Prenatal and postnatal growth and development of the central nervous system of the pig. Proc Royal Soc Lond B. 1967;166(1005):384-95

85. Dobbing J, Sands J. Comparative aspects of the brain growth spurt. Early Hum Dev. 1979;3:79-83.

86. Knickmeyer RC, Gouttard S, Kang C, et al. A structural MRI study of human brain development from birth to 2 years. J Neurosci. 2008:28(47):12176-82.

87. Conrad MS, Dilger RN, Johnson RW. Brain growth of the domestic pig (Sus scrofa) from 2 to 24 weeks of age: a longitudinal MRI study. Dev Neurosci. 2012:34(4):291-8. 
88. Conrad MS, Dilger RN, Nickolls A, Johnson RW. Magnetic resonance imaging of the neonatal piglet brain. Pediatr Res. 2012;71(2):179-84.

89. Saikali S, Meurice P, Sauleau P, et al. A three-dimensional digital segmented and deformable brain atlas of the domestic pig. J Neurosci Methods. 2010;192(1):102-9.

90. Munkeby BH, De Lange C, Emblem KE, et al. A piglet model for detection of hypoxic-ischemic brain injury with magnetic resonance imaging. Acta Radiol. 2008;49(9):1049-57.

91. Fang M, Lorke DE, Li J, Gong X, Yew JC, Yew DT. Postnatal changes in functional activities of the pig's brain: a combined functional magnetic resonance imaging and immunohistochemical study. Neurosignals. 2005;14(5):222-33.

92. Looi T, Piorkowska K, Mougenot C, Waspe A, Hynynen K, Drake J. An MR-based quantitative intraventricular hemorrhage porcine model for MR-guided focused ultrasound thrombolysis. Childs Nerv Syst. 2018;34(9):1643-50

93. Tang T, Weiss MD, Borum P, Turovets S, Tucker D, Sadleir R. In vivo quantification of intraventricular hemorrhage in a neonatal piglet model using an EEG-layout based electrical impedance tomography array. Physiol Meas. 2016;37(6):751-64

94. Felix B, Leger M-E, Albe-Fessard D. Stereotaxic atlas of the pig brain. Brain Res Bull. 1999:49(1-2):1-138.

95. Sauleau P, Lapouble E, Val-Laillet D, Malbert $\mathrm{CH}$. The pig model in brain imaging and neurosurgery. Animal. 2009;3(8):1138-51.

96. Fleming SA, Dilger RN. Young pigs exhibit differential exploratory behavior during novelty preference tasks in response to age, sex, and delay. Behav Brain Res. 2017:321:50-60.

97. Dilger RN, Johnson RW. Behavioral assessment of cognitive function using a translational neonatal piglet model. Brain Behav Immun. 2010;24(7):1156-65.

98. Fleming SA, Monaikul S, Patsavas AJ, Waworuntu RV, Berg BM, Dilger RN. Dietary polydextrose and galactooligosaccharide increase exploratory behavior, improve recognition memory, and alter neurochemistry in the young pig. Nutr Neurosci. 2017;22(7):499-512.

99. Radlowski EC, Conrad MS, Lezmi S, et al. A neonatal piglet model for investigating brain and cognitive development in small for gestational age human infants. PLoS ONE. 2014;9(3): e91951.

100. Cohen LA. Abscence of a foramen of Magendie in the dog, cat, rabbit, and goat. Arch Neurol. 1967;16:524.

101. Blake JA. The roof and lateral recesses of the fourth ventricle, considered morphologically and embryologically. J Comp Neurol. 1900;10:79.

102. Dombrowski SM, Leichliter A, Deshpande A, Dingwall C, Leibson Z, Luciano MG. Hydrocephalus-induced ischemia relating to VEGF-R2 and blood vessel density in hippocampus. Cerebrospinal Fluid Res. 2006;3(Suppl 1):S20.

103. Takei F, Shapiro K, Kohn I. Influence of the rate of ventricular enlargement on the white matter water content in progressive feline hydrocephalus. J Neurosurg. 1987;66(4):577-83.

104. Luciano MG, Dombrowski SM, Qvarlander S, et al. Novel method for dynamic control of intracranial pressure. J Neurosurg. 2016;126(5):1629-46.

105. Park EH, Dombrowski S, Luciano M, Zurakowski D, Madsen JR. Alterations of pulsation absorber characteristics in experimental hydrocephalus. J Neurosurg Pediatr. 2010;6(2):159-70.

106. Dombrowski SM, Schenk S, Leichliter A, Leibson Z, Fukamachi K, Luciano MG. Chronic hydrocephalus-induced changes in cerebral blood flow: mediation through cardiac effects. J Cereb Blood Flow Metab. 2006;26(10):1298-310.

107. Zou R, Park EH, Kelly EM, Egnor M, Wagshul ME, Madsen JR. Intracranial pressure waves: characterization of a pulsation absorber with notch filter properties using systems analysis: laboratory investigation. J Neurosurg Pediatr. 2008;2(1):83-94.

108. Wagshul ME, Egnor MR, Kelly EJ, Yu HJ. Resonance and intracranial pressure pulsations: an experimental study. Clin Neurol Neurosurg. 2008;110(1):S5.
109. Williams MA, McAllister JP, Walker ML, et al. Priorities for hydrocephalus research: report from a National Institutes of Health-sponsored workshop. J Neurosurg. 2007;107(5 Suppl):345-57.

110. McComb JG, Davson H, Hyman S, Weiss MH. Cerebrospinal fluid drainage as influenced by ventricular pressure in the rabbit. J Neurosurg. 1982;56(6):790-7

111. Erlich SS, McComb JG, Hyman S, Weiss MH. Ultrastructural morphology of the olfactory pathway for cerebrospinal fluid drainage in the rabbit. J Neurosurg. 1986:64:466-73.

112. McComb JG, Hyman S, Weiss MH. Lymphatic drainage of cerebrospinal fluid in the cat. In: Shapiro K, Marmarou A, Portnoy H, editors. Hydrocephalus. Skinidin: Raven Press; 1984. p. 83-97.

113. Nagra G, Wagshul ME, Rashid S, Li J, MCAllister JP 2nd, Johnston M. Elevated CSF outflow resistance associated with impaired lymphatic CSF absorption in a rat model of kaolin-induced communicating hydrocephalus. CSF Res. 2010;7(1):4

114. Nagra G, Li J, McAllister JP 2nd, Miller J, Wagshul M, Johnston M. Impaired lymphatic cerebrospinal fluid absorption in a rat model of kaolin-induced communicating hydrocephalus. Am J Physiol Regul Integr Comp Physiol. 2008;294(5):R1752-9.

115. Koh L, Nagra G, Johnston M. Properties of the lymphatic cerebrospinal fluid transport system in the rat: impact of elevated intracranial pressure. J Vasc Res. 2007;44(5):423-32.

116. Nagra G, Johnston MG. Impact of ageing on lymphatic cerebrospinal fluid absorption in the rat. Neuropathol App Neurobiol. 2007;33(6):684-91.

117. Koh L, Zakharov A, Nagra G, Armstrong D, Friendship R, Johnston M Development of cerebrospinal fluid absorption sites in the pig and rat: connections between the subarachnoid space and lymphatic vessels in the olfactory turbinates. Anat Embryol. 2006;211(4):335-44.

118. Nagra G, Koh L, Zakharov A, Armstrong D, Johnston M. Quantification of cerebrospinal fluid transport across the cribriform plate into lymphatics in rats. Am J Physiol Reg Integr Comp Physiol. 2006;291(5):R1383-9.

119. Zakharov A, Papaiconomou C, Djenic J, Midha R, Johnston M. Lymphatic cerebrospinal fluid absorption pathways in neonatal sheep revealed by subarachnoid injection of Microfil. Neuropathol App Neurobiol. 2003;29(6):563-73.

120. Brix MK, Westman E, Simmons A, et al. The Evans' Index revisited: new cut-off levels for use in radiological assessment of ventricular enlargement in the elderly. Eur J Radiol. 2017:95:28-32.

121. Morales DM, Holubkov R, Inder TE, et al. Cerebrospinal fluid levels of amyloid precursor protein are associated with ventricular size in post-hemorrhagic hydrocephalus of prematurity. PLOS ONE. 2015;10(3): e0115045.

122. Mandell JG, Kulkarni AV, Warf BC, Schiff SJ. Volumetric brain analysis in neurosurgery: part 2. Brain and CSF volumes discriminate neurocognitive outcomes in hydrocephalus. J Neurosurg Pediatr. 2015;15(2):125-32.

123. Nikas DC, Post AF, Choudhri AF, et al. Pediatric hydrocephalus: systematic literature review and evidence-based guidelines. Part 10: change in ventricle size as a measurement of effective treatment of hydrocephalus. J Neurosurg Pediatr. 2014;14(Suppl 1):77-81.

124. Warf B, Ondoma S, Kulkarni A, et al. Neurocognitive outcome and ventricular volume in children with myelomeningocele treated for hydrocephalus in Uganda. J Neurosurg Pediatr. 2009:4(6):564-70.

125. Rekate HL. Classification of hydrocephalus. In: Cinalli G, Ozek MM, Sainte-Rose C, editors. Pediatric hydrocephalus. Cham: Springer; 2018. p. 1-17.

\section{Publisher's Note}

Springer Nature remains neutral with regard to jurisdictional claims in published maps and institutional affiliations. 